\title{
Tumorigenic proteins upregulated in the MYCN-amplified IMR-32 human neuroblastoma cells promote proliferation and migration
}

\author{
HAYAT ZAATITI $^{1 *}$, JAD ABDALLAH $^{2 *}$, ZEINA NASR $^{1}$, GEORGE KHAZEN $^{3}$, \\ ANTHONY SANDLER ${ }^{4}$ and TAMARA J.ABOU-ANTOUN ${ }^{2}$ \\ ${ }^{1}$ Department of Biology, Faculty of Sciences, University of Balamand, El-Koura; ${ }^{2}$ Department of Pharmaceutical Sciences, \\ School of Pharmacy, and ${ }^{3}$ School of Arts and Sciences, Lebanese American University, Byblos 1102-2801, Lebanon; \\ ${ }^{4}$ Sheikh Zayed Institute for Pediatric Surgical Innovation, Joseph E. Robert Jr. Center for Surgical Care, \\ Children's National Medical Center, Washington, DC 20010, USA
}

Received September 20, 2017; Accepted December 5, 2017

DOI: 10.3892/ijo.2018.4236

\begin{abstract}
Childhood neuroblastoma is one of the most common types of extra-cranial cancer affecting children with a clinical spectrum ranging from spontaneous regression to malignant and fatal progression. In order to improve the clinical outcomes of children with high-risk neuroblastoma, it is crucial to understand the tumorigenic mechanisms that govern its malignant behaviors. MYCN proto-oncogene, bHLH transcription factor $(M Y C N)$ amplification has been implicated in the malignant, treatment-evasive nature of aggressive, highrisk neuroblastoma. In this study, we used a SILAC approach to compare the proteomic signatures of $M Y C N$-amplified IMR-32
\end{abstract}

Correspondence to: Dr Tamara J. Abou-Antoun, Department of Pharmaceutical Sciences, School of Pharmacy, Lebanese American University, Blat, LAU main road, Byblos 1102-2801, Lebanon

E-mail: tamara.abouantoun@lau.edu.lb

${ }^{*}$ Contributed equally

Abbreviations: APP, amyloid precursor protein; ANK1 and ANK2, Ankyrin 1 and 2; AURKA/B, Aurora kinase A and B; BIRC, baculoviral IAP repeat containing 5 (survivin); CDK1, cyclin-dependent kinase 1 ; CDCA8, cell division cycle associated 8; CNTN2, contactin 2; EGFR, epidermal growth factor receptor; E2F1, E2F transcription factor 1; EZR, Ezrin; FABP5, fatty-acid binding protein 5; HIF-1 $\alpha$, hypoxiainducible factor-1 $\alpha$; HMGA1, high mobility group protein A1; IL3, interleukin 3; IPA, Ingenuity Pathway Analysis; KITLG, KIT ligand; L1-CAM, L1-cell adhesion molecule; MYCN, MYCN proto-oncogene, bHLH transcription factor; NCAM1, neural cell adhesion molecule 1; NCAN, neurocan; NRP1, neuropilin-1; RANBP9, RAN binding protein 9; RDX, radixin; SP1, Sp1 transcription factor; SREBF1 or 2, sterol regulatory element binding transcription factor 1 or 2

Key words: neuroblastoma, high mobility group protein A1, L1-cell adhesion molecule, fatty-acid binding protein 5, survivin and non-MYCN-amplified SK-N-SH human neuroblastoma cells. Tumorigenic proteins, including fatty-acid binding protein 5 (FABP5), L1-cell adhesion molecule (L1-CAM), baculoviral IAP repeat containing 5 [BIRC5 (survivin)] and high mobility group protein A1 (HMGAl) were found to be significantly upregulated in the IMR-32 compared to the SK-N-SH cells and mapped to highly tumorigenic pathways including, $M Y C, M Y C N$, microtubule associated protein Tau (MAPT), E2F transcription factor $1(E 2 F 1)$, sterol regulatory element binding transcription factor 1 or 2 (SREBF 1/2), hypoxiainducible factor $1 \alpha(H I F-1 \alpha)$, Spl transcription factor $(S P 1)$ and amyloid precursor protein $(A P P)$. The transcriptional knockdown (KD) of MYCN, HMGA1, FABP5 and L1-CAM significantly abrogated the proliferation of the IMR-32 cells at $48 \mathrm{~h}$ post transfection. The early apoptotic rates were significantly higher in the IMR-32 cells in which FABP5 and MYCN were knocked down, whereas cellular migration was significantly abrogated with FABP5 and HMGA1 KD compared to the controls. Of note, L1-CAM, HMGAl and FABP5 KD concomitantly downregulated $M Y C N$ protein expression and MYCN KD concomitantly downregulated L1-CAM, HMGAl and $F A B P 5$ protein expression, while survivin protein expression was significantly downregulated by $M Y C N, H M G A 1$ and $F A B P 5 \mathrm{KD}$. In addition, combined $L 1-C A M$ and FABP5 KD led to the concomitant downregulation of $H M G A l$ protein expression. On the whole, our data indicate that this inter-play between $M Y C N$ and the highly tumorigenic proteins which are upregulated in the malignant IMR-32 cells may be fueling their aggressive behavior, thereby signifying the importance of combination, multi-modality targeted therapy to eradicate this deadly childhood cancer.

\section{Introduction}

Neuroblastoma is a malignancy caused by the hyperplasia of naive neural crest cells (1). It is the most common solid tumor affecting children $<5$ years of age, and the third most common cause of pediatric cancer-related mortality (2), accounting for $7 \%$ of childhood malignancies and $15 \%$ of childhood 
cancer-related mortalities (3). The disease is known for its broad range of clinical behavior and variable responses to treatment (4). This clinical heterogeneity is elucidated by the fact that some neuroblastomas can spontaneously regress or differentiate into a benign form, ganglioneuroma, while others are not responsive to current therapies (5). Even though the prognosis for children with neuroblastoma is generally good, the survival rates for children with high-risk neuroblastomas are still poor, despite advanced therapeutic strategies (6).

Several transcription factors have been shown to be involved in the pathogenesis of neuroblastoma by enhancing cancer cell proliferation (7). MYCN proto-oncogene, bHLH transcription factor $(M Y C N)$, one of these transcription factors, is a phosphoprotein in the MYC family of transcription factors, encoded by the $M Y C N$ oncogene (7). The amplification of $M Y C N$ is one of the first most important genetic signatures of neuroblastoma (8). Patients with neuroblastoma carrying a $M Y C N$ amplification are classified in the high-risk group, and their 5-year overall survival rate following diagnosis does not exceed 50\% (9). An amplification leading to the aberrant expression of $M Y C N$ has been associated with tumor aggressiveness, resistance to chemotherapy and the inability to differentiate (10). In fact, $M Y C N$ amplification confers cell resistance to apoptosis induced by the tumor necrosis factor-related apoptosis-inducing ligand system (11), whereas $M Y C N$ silencing promotes proliferation arrest, differentiation and the apoptosis of human neuroblastoma cells (12).

In the present study, we conducted a pilot proteomics analysis to compare the proteomic signature of the $M Y C N$ amplified IMR-32 cells to that of the non-MYCN-amplified SK-N-SH human neuroblastoma cells using stable isotope labeling by amino acids in cell culture (SILAC) strategy (13). Of the differentially expressed proteins (based on expression value and fold change) between the IMR-32 and SK-N-SH cells, we were particularly interested in proteins upregulated in the IMR-32 compared to the SK-N-SH cells that mapped to upstream regulators [ $M Y C N, M Y C$, hypoxia-inducible factor-1 $\alpha(H I F-1 \alpha)$, E2F transcription factor $1(E 2 F 1)$, Sp1 transcription factor (SP1), KIT ligand (KITLG), interleukin 3 (IL3), amyloid precursor protein $(A P P)$, insulin receptor (INSR) and sterol regulatory element binding transcription factor 1 or 2 (SREBF1/2)] predicted by Ingenuity Pathway Analysis (IPA; Ingenuity Systems, Inc., Redwood City, CA, USA; 2000-2014) to be activated in the IMR-32 cells. These included: L1 cell adhesion molecule (L1-CAM); high mobility group protein A1 (HMGAl); fatty acid-binding protein 5 ( $F A B P 5)$; and baculoviral IAP repeat containing 5 [BIRC5 (survivin)].

In the present study, we aimed to determine the interaction between the above-mentioned molecules and $M Y C N$ in the IMR-32 cells and the effect of transcriptional knockdown (KD) of these targets on cellular proliferation, migration and apoptosis. We also wished to determine the cellular bio-function after single-target versus double-target transcriptional KD of the said proteins and whether an added effect would be observed. In addition, we were interested in examining whether a crosstalk exists between these proteins as determined by differential protein expression levels of one target after transcriptional KD of each of the other targets.

\section{Materials and methods}

Reagents and human cell lines. The IMR-32 (MYCNamplified) and SK-N-SH (non-MYCN-amplified) cells are human neuroblastoma/neuroepthelioma cell lines purchased from the American Type Culture Collection (ATCC, Manassas, VA, USA) where routine STR testing was conducted and the cells were confirmed to derive from human species. In addition, the cells were routinely tested for mycoplasma, aerobic and anaerobic bacteria, and human pathogenic viruses including human immunodeficiency virus (HIV), hepatitis B (HepB), human papilloma virus (HPV), Epstein-Barr virus (EBV) and cytomegalovirus (CMV), all of which our cells tested negative for and were used within 6 months of purchase from ATCC. The cells were cultured in minimal essential Eagle's medium (EMEM; cat. no. M2279) supplemented with $2 \mathrm{mM}$ L-glutamine (cat. no. 7513; Sigma, St. Louis, MO, USA), $2 \%$ penicillin streptomycin (cat. no. P4333SIGMA), $1 \mathrm{mM}$ sodium pyruvate (cat. no. S8636), $2 \%$ non-essential amino acids (cat. no. M7145) and 10\% fetal bovine serum (cat. no. F9665) (all from Sigma). The cells were cultured to $80 \%$ confluence in T25 flasks at $5 \% \mathrm{CO}_{2}$ and $37^{\circ} \mathrm{C}$. The medium was replenished every $48 \mathrm{~h}$. After 8 days, the cells covering $80 \%$ of the flask were collected and transferred into a $15 \mathrm{ml}$ falcon tube to be centrifuged at $200 \mathrm{x} \mathrm{g}$ for $10 \mathrm{~min}$ at $4^{\circ} \mathrm{C}$. The old medium was discarded and the cells were re-suspended in $10 \mathrm{ml}$ of fresh medium and transferred into a T75 flask. The cells harvested from T75 flasks were frozen in Corning ${ }^{\circledR}$ Cryotubes (Corning Inc., New York, NY, USA) using 50\% fetal bovine serum (FBS), 40\% EMEM and 10\% DMSO (D2650; Sigma) to a final volume of $1 \mathrm{ml}$. The cryotubes were frozen first at $-80^{\circ} \mathrm{C}$ for $24 \mathrm{~h}$ in isopropanol to provide a gradual decrease in temperature. They were then transferred to liquid nitrogen for long term storage.

SILAC proteomics sample preparation. The IMR-32 and SK-N-SH neuroblastoma cells were grown in the standard culture conditions until they reached confluency after which they were washed 6 times with serum-free medium and then cultured in serum-free medium supplemented with 'heavy' isotopes where arginine and lysine were replaced with ${ }^{13} \mathrm{C}_{6}$ - $\mathrm{Arg}$ and ${ }^{13} \mathrm{C}_{6},{ }^{15} \mathrm{~N}_{2}$-Lys (Cambridge Isotopes, Andover, MA, USA) for 6 doublings to ensure incorporation of the isotopes into the entire cellular population. After 6 doublings, the cells were collected, lysed, quantified and mixed together into one SuperSILAC mastermix cocktail and saved at $-80^{\circ} \mathrm{C}$. The cells were then cultured in serum-free growth medium supplemented with 'light' isotopes where arginine and lysine were replaced with ${ }^{12} \mathrm{C}_{6}$-Arg and ${ }^{12} \mathrm{C}_{6},{ }^{14} \mathrm{~N}_{2}$-Lys until they reached $\sim 80 \%$ confluency. The cells were lysed at that point and quantified, and a 'spike-in' strategy used to spike-in the 'heavy' labeled cellular lysates into the 'light' labeled cellular lysates at a 1:1 ratio. Approximately $100 \mu \mathrm{g}$ of total protein mixture (50:50 $\mu \mathrm{g}$ of cell lysate:SuperSILAC cocktail) was loaded onto a $4-12 \%$ polyacrylamide gel and electrophoresed until the proteins were well-separated. The gel was fixed and stained with Commassie Blue (Bio-Rad, Hercules, CA, USA) then de-stained overnight in $\mathrm{H}_{2} \mathrm{O}$ at $4^{\circ} \mathrm{C}$. The gels were then sliced into $\sim 35-40$ bands which underwent in-gel digestion with trypsin (Promega, Madison, WI, USA) using a previously documented protocol (14) and 
the resultant peptides derived from each band were dried by vacuum centrifugation ( $240 \mathrm{x} \mathrm{g})$ at room temperature, and re-suspended in $6 \mu 1$ of $0.1 \%$ TFA for analysis by mass spectrometry and proteomics analysis as previously described (15).

Mass spectrometry analysis and protein identification and quantification. The methods used to conduct the mass spectrometry and protein identification and quantification were exactly as described in the study by Formolo et al (15).

IPA, STRING protein networks and Enrichr analysis tool. Ingenuity Systems, Inc. 2000-2014 (content version, 18030641; release date, December 6, 2013) was used to derive the target molecules within the data set, upstream regulators, molecule type, predicted activation status with activation z-score and $\mathrm{P}$-values of the proteins differentially expressed between the IMR-32 and SK-N-SH cells based on expression of and number of peptides detected per protein, where anything $>2$-fold is considered upregulated and anything below 0.5 -fold is considered downregulated. The Enrichr $(16,17)$ tool was used to annotate the differentially expressed proteins between the IMR-32 and SK-N-SH cells. Proteins in the network that were differentially expressed in the IMR-32 cells were mapped to the top diseases and bio-functions. Differential expression was determined as either upregulated ( $>2$-fold) or downregulated ( $<0.5$-fold) in the IMR-32 compared to the SK-N-SH cells. The STRING protein network tool was used to determine any interactions (experimentally determined, from curated databases and text-mining) between our proteins of interest.

Protein extraction for validation by western blot analysis. The IMR32 and SK-N-SH cells were collected into $15-\mathrm{ml}$ falcon tubes and centrifuged at $200 \mathrm{x} \mathrm{g}$ for $10 \mathrm{~min}$ at $4^{\circ} \mathrm{C}$. The medium was discarded and the pellet was washed twice with Dulbecco's phosphate-buffered saline (PBS; D8537; Sigma). PBS was then discarded and the cells were incubated on ice for $40 \mathrm{~min}$ with $120 \mu \mathrm{l}$ of lysis buffer (for a confluent T75 flaks) composed of $50 \mathrm{Mm}$ tris- $\mathrm{HCl}$ (pH 7.5), 1 mM EDTA, $250 \mathrm{mM}$ $\mathrm{NaCl}, 50 \mathrm{mM} \mathrm{NaF}, 0.1 \mathrm{mM} \mathrm{Na} \mathrm{VO}_{4}, 0.5 \%$ Titron X-100 and 1X protease inhibitor cocktail (cat no. 11697498001; Roche, Indianapolis, IN, USA). The lysates were transferred to Eppendorf tubes where they were centrifuged at $4^{\circ} \mathrm{C}$ for $20 \mathrm{~min}$ at $8,000 \mathrm{x} \mathrm{g}$ to eliminate cellular debris. The supernatants were then transferred to new Eppendorf tubes where they were mixed with $60 \mu \mathrm{l}$ of the $3 \mathrm{X}$ sample buffer $(0.5 \mathrm{M}$ tris- $\mathrm{HCl}$, glycerol, $10 \%$ SDS, $\beta$-mercaptoethanol and $0.05 \%$ bromophenol blue) in preparation for western blot analysis.

Western blot analysis. Protein expression was confirmed by western blot analysis as previously described (18). Briefly, For L1-CAM, glyceraldehyde 3-phosphate dehydrogenase $(G A P D H)$ and $H M G A 1$ detection, a $10 \%$ polyacrylamide (cat. no. 161-0156; Bio-Rad) gel was used; however, for FABP5 and $M Y C N$ detection a $12 \%$ polyacrylamide gel was used. A $5 \%$ stacking gel was used to form the wells. The extracted proteins were separated on gels using a current of $150 \mathrm{mV}$. Proteins were then transferred to a PVDF membrane (cat. no. 1620177; Bio-Rad) for $90 \mathrm{~min}$ at $100 \mathrm{mV}$ which was then blocked using 5\% BSA (cat. no. A2153-100G; Sigma) diluted in $1 \mathrm{X}$ TBS with $1 \%$ Tween-20 (cat. no. 9005-64-5).
The blots were incubated with rabbit monoclonal L1-CAM (cat. no. ab20148), HMGA1 (cat. no. ab129153), FABP5 (cat. no. ab84028), survivin (cat. no. ab469) (all from Abcam, Cambridge MA, USA) and MYCN antibodies (cat. no. 9405; Cell Signaling Technology, Danvers, MA, USA) and with mouse monoclonal GAPDH antibody (cat. no. ab9484) (Abcam) overnight (all diluted 1:1,000 in TBS-T +5\% BSA blocking solution). The blots were washed 5 times for $5 \mathrm{~min}$ with TBST and then incubated with secondary antibodies [goat anti-rabbit (cat. no. 170-5046) or goat anti-mouse (cat. no. 170-5047) HRP-conjugated secondary antibodies from Bio-Rad] for $1 \mathrm{~h}$. After washing, the blots were incubated with Clarity Western ECL substrate (cat. no. 1705060; Bio-Rad) for 3 min and imaged using the Bio-Rad ${ }^{\odot}$ ChemiDoc system and analyzed using ImageLab ${ }^{\circledR}$ software. The bands obtained were normalized to GAPDH.

Transcriptional KD of target proteins. The 4 siRNA oligonucleotides for L1-CAM (Hs L1-CAM_4 SI00009296, Hs L1-CAM_3 SI00009289, Hs L1-CAM_2 SI00009282 and Hs L1-CAM_1SI00009275; Qiagen, Valencia, CA, USA), HMGA1 (D-004597-01 HMGA1, D-004597-02 HMGA1, D-004597-03 HMGAl and D-004597-18 HMGA1; Dharmacon, Lafayette, CO, USA), MYCN (Hs_MYCN_7 SI03113670, Hs_MYCN_6 SI03087518, Hs_MYCN_5 SI03078222 and Hs_MYCN_3 SI00076300; Qiagen) and FABP5 (Hs_FABP5_10 SI04277553, Hs_FABP5_9 SI04210948, Hs_FABP5_8 SI04210941 and Hs_FABP5_5 SI03145835; Qiagen) were reconstituted in RNAase-free water to a final concentration of $10 \mu \mathrm{M}$. A total of $5 \times 10^{5}$ cells were seeded in each well of a 6 -well plate in a final volume of $2 \mathrm{ml}$ of antibiotics-free medium. The cells were transfected with the siRNA using the fast-forward Hiperfect transfection protocol following the manufacturer's instructions (cat. no. 301705; Qiagen). A final concentration of $100 \mathrm{nM}$ of each siRNA was achieved by mixing $10 \mu \mathrm{l}$ of the $10 \mu \mathrm{M}$ siRNA with $10 \mu \mathrm{l}$ of Hiperfect (cat. no. 301705; Qiagen) and $370 \mu \mathrm{l}$ of OptiMEM (cat. no. 31985-062; Life Technologies, Carlsbad, CA, USA). The mixture was incubated at room temperature for $20 \mathrm{~min}$, and added in a drop-wise manner to the corresponding wells. The negative control was prepared by treating the cells with $90 \mu \mathrm{l}$ of OptiMEM and $10 \mu \mathrm{l}$ of Hiperfect. The cells were then incubated with the siRNAs for $48 \mathrm{~h}$, lysed and processed for western blot analysis.

WST-1 cell proliferation assay. In order to examine the effects of KD on cellular proliferation, a WST-1 cell proliferation assay was conducted. A total of $5 \times 10^{4}$ cells were cultured in each well of a 96-well plate in a final volume of $100 \mu \mathrm{l}$. Duplicates of each condition were prepared. The cells were transfected with L1-CAM, HMGA1, MYCN, FABP5 or scrambled siRNAs in a final concentration of $100 \mathrm{nM}$. The cells were incubated in $100 \mu \mathrm{l}$ growth medium for 24,48 and $72 \mathrm{~h}$ and treated with $10 \mu \mathrm{l}$ of WST-1 reagent (cat. no. ab155902; Abcam) per well prior to reading. The absorbance was detected after $3 \mathrm{~h}$ using an Epoch $^{\text {TM }}$ Microplate Spectrophotometer at $450 \mathrm{~nm}$ (BioTek, Winooski, VT, USA).

Annexin V-FITC/propidium iodide (PI) apoptosis detection assay. The IMR32 cells were cultured in a 6-well plate $\left(5 \times 10^{5}\right.$ cells/well), and transfected with the various siRNA 
constructs as described above. Negative control cells were either unlabeled/untreated or Annexin V-FITC- and PI-labeled and untreated. Positive control cells were transfected with $100 \mathrm{nM}$ siRNA of our target constructs and labeled with Annexin V-FITC and PI or Annexin V-FITC alone. The cells were then collected at $48 \mathrm{~h}$ using accutase (cat. no. A11105-01; Thermo Fisher Scientific, Waltham, MA, USA) and centrifuged at $200 \times \mathrm{g}$ for $5 \mathrm{~min}$ at $4^{\circ} \mathrm{C}$. They were then re-suspended in $500 \mu \mathrm{l}$ of $1 \mathrm{X}$ binding buffer, treated with $5 \mu \mathrm{l}$ of Annexin V-FITC or PI from Abcam (cat. no. ab14085) and incubated in the dark for $5 \mathrm{~min}$ prior to flow cytometric analysis using FACSCalibur flow cytometer (BD Biosciences, San Jose, CA, USA). Data were analyzed using IQuest Pro software (version 5.1) (BD Biosciences). IMR32 cells were identified by their forward-scatter (FSC) and side-scatter (SSC) characteristics. Viable, early apoptotic, late apoptotic and dead cell populations were identified as Annexin $\mathrm{V}^{-} / \mathrm{PI}^{-}$, Annexin $\mathrm{V}^{+} / \mathrm{PI}^{-}$, Annexin $\mathrm{V}^{+} / \mathrm{PI}^{+}$and Annexin $\mathrm{V}^{-} / \mathrm{PI}^{+}$, respectively. Cells stained with Annexin V-FITC or PI alone were used to adjust color compensation settings on flow cytometer. A minimum of 20,000 cell events were recorded for each sample.

Wound healing migration assay. The IMR-32 cells were grown to $\sim 70 \%$ confluency in triplicates of 12 -well plates in standard culture medium and conditions. FABP5 or HMGA1 siRNA transfection was conducted as described above and after $24 \mathrm{~h}$, the cells were scraped down the midline of the plate to resemble a 'wound'. The cells which were scraped off were washed $2 \mathrm{X}$ with serum-free medium and fresh medium replenished and the cells were then imaged ( $0 \mathrm{~h}$ time-point) and cultured under standard growth culture conditions for $24 \mathrm{~h}$. The cells were then imaged at several random fields down the scratched 'wound' area and the area $\left(\mu \mathrm{M}^{2}\right)$ of 'wound-closure' after $24 \mathrm{~h}$ in siRNA KD-compared to control siRNA-transfected cells was measured using AxioVision Systems software (Zeiss, Oberkochen, Germany). The average of the areas of multiple random fields was represented as a fold change compared to untransfected controls and graphed using Microsoft Excel software.

Statistical analysis. Experiments were conducted in triplicate, repeated 3 independent times and the means \pm the standard error of the means (SEM) of all 3 experiments was calculated and plotted. A two-sided Student's t-test was used to determine statistically significant differences between groups. A one-way analysis of variance (ANOVA) test was used followed by a post hoc Fisher's least significant difference (LSD) test to determine the significance among the means of multiple groups obtained from $\geq 3$ independent experiments. The means \pm SEM of 3 or more experiments was derived and graphed using Microsoft Excel software. Statistical significance was set at a P-value $<0.05$.

\section{Results}

Top networks, diseases and bio-functions to which overexpressed proteins in IMR-32 cells are mapped. We conducted preliminary proteomics analysis of the $M Y C N$-amplified IMR-32 compared to the non-MYCN-amplified SK-N-SH human neuroblastoma cell lines using a highly quantitative
SILAC methodology. The significant, differentially expressed proteins were then annotated using IPA in order to predict the upstream regulators of highly tumorigenic proteins in the IMR-32 compared to the SK-N-SH cells. The total numbers of differentially expressed proteins were found to be 875 out of 4,960 proteins (either $>2$-fold upregulated or $<0.5$-fold downregulated) in the IMR-32 compared to the SK-N-SH cells. These proteins were affiliated with upstream regulators that IPA predicted to be activated in the IMR-32 compared to the SK-N-SH cells based on the molecules identified in our dataset (data not shown).

Table I lists the top diseases and disorders, molecular and cellular bio-functions, as well as physiological system development and function categories that proteins significantly overexpressed in the IMR-32 cells are mapped to; the fold change cut-off was set at $\geq 2$-fold. Renal and urological, neurological, hereditary and infectious diseases, as well as organismal injury and abnormalities, were among the top disease categories that the proteins were mapped to Table IA. RNA post-transcriptional modification, molecular transport, RNA trafficking, cellular compromise and gene expression were among the top molecular and cellular functions that the overexpressed proteins in the IMR-32 cells were mapped to Table IB. The physiological system development and function categories that proteins belonged to included tissue development, nervous system development and function, connective tissue development and function and embryonic development (Table IC).

Fold change and predicted activated up-stream regulators of proteins overexpressed in IMR-32 compared to SK-N-SH cells. IPA was used to predict the activation status of the upstream regulators of the differentially expressed proteins between the IMR-32 and SK-N-SH cells. Table II lists the top molecules and the fold change of upregulated proteins which included, CaM kinase like vesicle associated (CAMKV), tumor protein D52 (TPD52), argininosuccinate synthetase 1 (ASS1), FABP6, L1-CAM, FABP5, DNA polymerase $\gamma$, catalytic subunit $(P O L G)$, collapsin response mediator protein 1 (CRMP1), ribonuclease $\mathrm{H} 2$ subunit $\mathrm{B}($ RNASEH $2 B)$ and $\mathrm{G}$ protein subunit $\alpha \mathrm{O} 1$ (GNAO1). MYCN, hepatocyte nuclear factor $4 \alpha$ (HNF4A), microtubule associated protein Tau (MAPT), APP and $E 2 F$ were predicted to be activated upstream regulators of the proteins in this dataset, as determined by IPA (based on the target molecules that were found to be $>2$-fold upregulated in the IMR-32 compared to the SK-N-SH cells). In addition to the top upstream regulators, Table III lists additional upstream regulators predicted to be activated or inhibited in the IMR-32 compared to the SK-N-SH cells. Of note, is the activation of cancer-promoting, angiogenic and cancer stemness players, such as $M Y C, H I F-1 \alpha$, eukaryotic translation initiation factor $4 \gamma 1$ (EIF4G1), IL3, angiopoietin 2 (ANGPT2) and SREBF in the IMR-32 cells. Molecules predicted to be inhibited in the IMR-32 compared to the SK-N-SH cells included Aly/REF export factor (ALYREF), Ankyrin (ANK)2, autophagy related 7 (ATG7), coiled-coil domain containing 88A (CCDC88A), chromatin target of PRMT1 (CHTOP), cleavage and polyadenylation specific factor 1 (CPSF1), CPSF2 and CPSF3 among others, primarily involved in RNA post-transcriptional modification, molecular transport and RNA trafficking. 
Table I. Functional annotation of proteins upregulated in the IMR-32 compared to the SK-N-SH human neuroblastoma cell lines.

A, Diseases and disorders

\begin{tabular}{lrr}
\hline Name & P-value & No. of molecules \\
\hline Infectious disease & $2.02 \mathrm{E}-09-1.69 \mathrm{E}-02$ & 135 \\
Organismal injury and abnormalities & $2.02 \mathrm{E}-09-1.89 \mathrm{E}-02$ & 164 \\
Renal and urological disease & $4.93 \mathrm{E}-09-1.69 \mathrm{E}-02$ & 70 \\
Hereditary disorder & $8.90 \mathrm{e}-07-1.89 \mathrm{e}-02$ & 41 \\
Neurological disease & $8.90 \mathrm{E}-07-1.75 \mathrm{E}-02$ & 98 \\
\hline
\end{tabular}

B, Molecular and cellular functions

\begin{tabular}{|c|c|c|}
\hline Name & P-value & No. of molecules \\
\hline RNA post-transcriptional modification & $2.54 \mathrm{E}-33-1.73 \mathrm{E}-02$ & 75 \\
\hline Molecular transport & 4.20E-11-1.73E-02 & 75 \\
\hline RNA trafficking & 4.20E-11-1.97E-02 & 23 \\
\hline Cellular compromise & $1.45 \mathrm{E}-10-1.90 \mathrm{E}-02$ & 38 \\
\hline Gene expression & 1.19E-07-1.07E-02 & 180 \\
\hline Associated network function & Score & \\
\hline $\begin{array}{l}\text { RNA post-transcriptional modification, molecular transport, } \\
\text { RNA trafficking }\end{array}$ & 45 & \\
\hline $\begin{array}{l}\text { Gene expression, RNA damage and repair, RNA } \\
\text { post-translational modification }\end{array}$ & 45 & \\
\hline $\begin{array}{l}\text { Cellular assembly and organization, cellular function and } \\
\text { maintenance, tissue development }\end{array}$ & 40 & \\
\hline Cellular movement, developmental disorder, hereditary disorder & 38 & \\
\hline Cellular compromise, cell cycle, cellular assembly and organization & 38 & \\
\hline
\end{tabular}

C, Physiological system development and function

\begin{tabular}{lcc}
\hline Name & P-value & No. of molecules \\
\hline Tissue development & $8.61 \mathrm{E}-06-1.57 \mathrm{E}-02$ & 70 \\
Nervous system development and function & $6.52 \mathrm{E}-05-1.73 \mathrm{E}-02$ & 75 \\
Connective tissue development and function & $7.68 \mathrm{E}-04-1.89 \mathrm{E}-02$ & 55 \\
Embryonic development & $7.68 \mathrm{E}-04-1.73 \mathrm{E}-02$ & 66 \\
\hline
\end{tabular}

Proteins overexpressed in the IMR-32 cells belong to tumorigenic pathways. The proteins overexpressed in the IMR-32 compared to the SK-N-SH cells that belonged to the upstream regulators predicted to be activated by IPA (SREBF1, SP1, SCAP, SREBF 2, IL3, KITLG, FLI1, INSR, $H I F-1 \alpha, M Y C, E I F 4 E$ and $A N G P T 2$ among others), mapped to signaling pathways that drive cancer stem cell maintenance and propagation (Notch) (19), invasion and metastasis [Racl/Pak1/p38/MMP-2 (20) and the leptin signaling pathway (21)], cancer malignancy [SREBP signaling (22) and the $A G E / R A G E$ pathway (23)] and proliferation [AMPK pathways (24)]. Table IV lists the upstream regulators predicted to be activated by IPA, with adjusted P-values for the overexpression level in the IMR-32 cells and the pathways in which these regulators have been demonstrated to play pivotal roles.
IMR-32 cells significantly overexpress the tumorigenic proteins, HMGA1, L1-CAM, FABP5 and BIRC5. Of the highly tumorigenic proteins identified to be upregulated in the IMR-32 compared to the SK-N-SH cells, we decided to focus our investigation on L1-CAM, HMGA1, FABP5, BIRC5 and $M Y C N$ as they mapped to several of the activated upstream regulators, as predicted by IPA and due to their tumorigenic roles played in various types of cancer as elaborated below in the 'Discussion'. Western blot analysis was used to determine the levels of HMGA1, FABP5, BIRC5 and L1-CAM, as well as $M Y C N$ protein expression between the IMR-32 and SK-N-SH cells. As expected, we found all these targets to be significantly overexpressed in the IMR-32 compared to the SK-N-SH neuroblastoma cells. Fig. $1 \mathrm{~A}$ is a representative demonstration of multiple western blotting experiments verifying the 

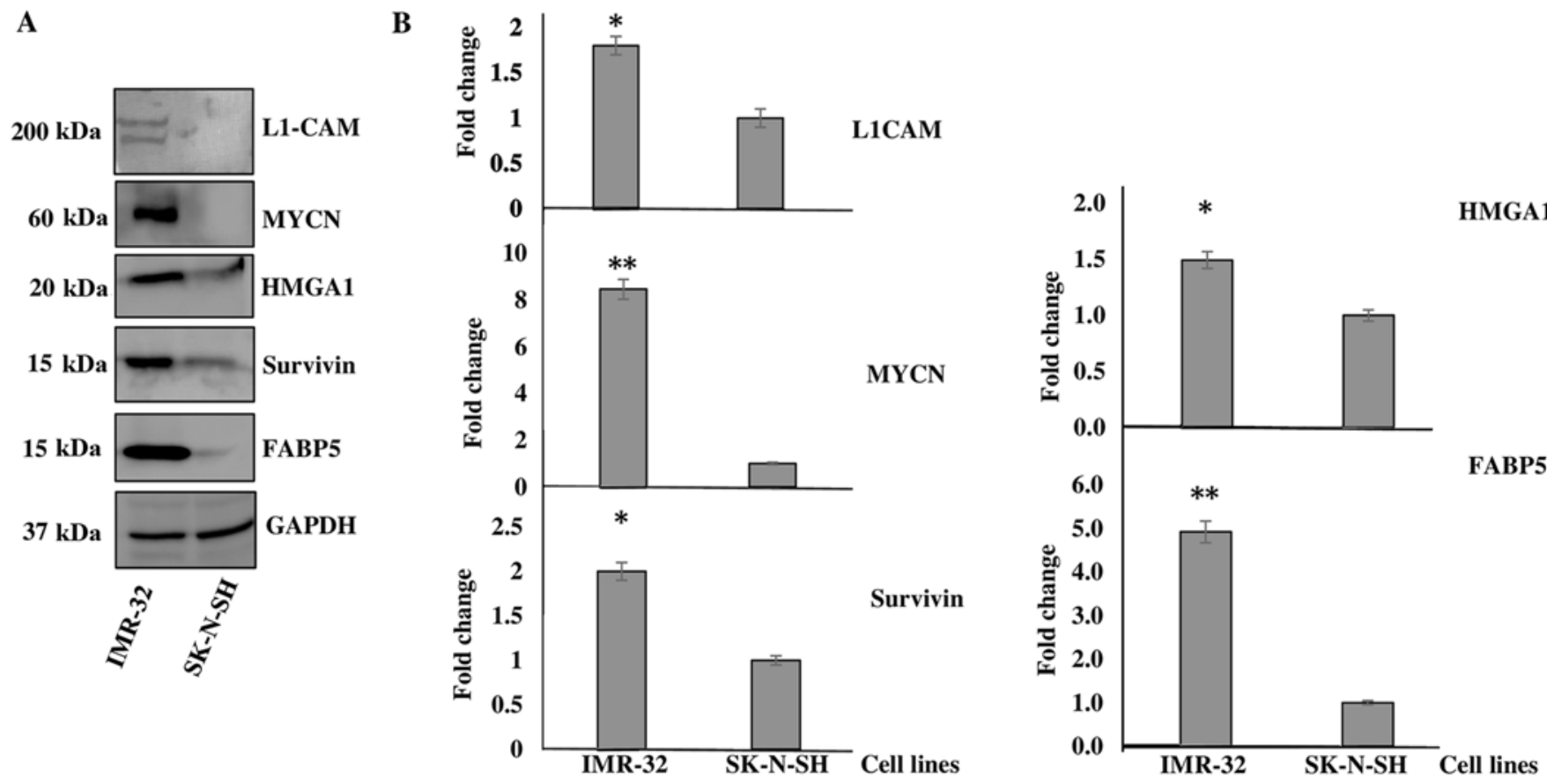

Figure 1. Verification of proteomics data. (A) Representative western blot images of L1-cell adhesion molecule (L1-CAM), MYCN proto-oncogene, bHLH transcription factor (MYCN), high mobility group protein A1 (HMGA1), survivin and fatty-acid binding protein 5 (FABP5) protein expression in the IMR-32 compared to the SK-N-SH cells. (B) Densitometric analysis verified the proteomics data and revealed the significant overexpression of L1-CAM, MYCN, HMGA1, survivin and FABP5 in the IMR-32 compared to the SK-N-SH cells. Experiments were run in triplicate and repeated $>3$ times. Results represent the means $\pm \mathrm{SEM} ;{ }^{*} \mathrm{P}<0.05$ and ${ }^{* *} \mathrm{P}<0.01$.

Table II. Fold change of top 10 proteins upregulated in the IMR-32 versus the SK-N-SH human neuroblastoma cells.

\begin{tabular}{lcc}
\hline Molecules & & Fold change \\
\hline CAMKV & & 103.800 \\
TPD52 & 39.976 \\
ASS1 & & 24.995 \\
FABP5 & & 18.000 \\
POLG & & 16.726 \\
L1-CAM & & 16.708 \\
CRMP1 & & 15.295 \\
FABP6 & & 15.268 \\
RNASEH2B & & 15.250 \\
GNAO1 & & 14.943 \\
\hline Upstream & P-value of & Activation \\
regulator & overlap predicted & state \\
\hline MYC & $1.52 \mathrm{E}-18$ & Activated \\
$H N F 4 A$ & $2.15 \mathrm{E}-15$ & \\
$M A P T$ & $7.36 \mathrm{E}-12$ & \\
$A P P$ & $1.10 \mathrm{E}-11$ & \\
E2F & $1.37 \mathrm{E}-11$ & \\
\hline
\end{tabular}

upregulation of these targets, as indicated by the SILAC proteomics data. Densitometric analysis revealed a significant upregulation of the protein expression of L1-CAM ( 1-fold overexpressed), MYCN ( 7-fold overexpressed), HMGAl
( 0.5-fold overexpressed), BIRC5 ( 1-fold overexpressed) and FABP5 ( 4-fold overexpressed) in the IMR-32 compared to the SK-N-SH cells (Fig. 1B).

Upregulated proteins in IMR-32 cells mapped to the highly tumorigenic MYCN pathway. The STRING protein network database was used to analyze the interactions (experimentally determined and from curated databases) between the activated upstream regulators of the overexpressed proteins in the IMR-32 cells (HMGA1, L1-CAM, BIRC5, FABP5, $M Y C, I N S R, S P I, H I F 1 A$ and SREBFI/2 among others) and $M Y C N$ (Fig. 2A). In addition, we used STRING protein network analysis to focus on the interactions between the activated upstream regulators, which our validated proteins (by western blot analysis; HMGA1, L1-CAM, FABP5 and BIRC5) mapped to Fig. 2B). Of particular interest, are the various hubs (proteins with multiple edges) identified, including INSR, SPI, HIF-1 $\alpha, M Y C, M Y C N, H M G A l$ and SREBF that show strong interactions (experimentally-determined, from curated databases and text-mining) with many other tumorigenic proteins (Fig. 2A). We further highlight the important interactions (experimentally determined, from curated databases and text-mining) between our validated targets (by western blot analysis; HMGA1, BIRC5 and MYCN) and the activated upstream regulators, SPI, SREBF1, MYC, KITLG, IL3, INSR and $H I F-1 \alpha$ (Fig. 2B). KEGG pathway analysis mapped the number of molecules to various pathways, most of which are known tumorigenic drivers, including PI3K/Akt, Ras, Rapl, $W n t, H I F-1 \alpha$, transforming growth factor- $\beta(T G F-\beta)$ and mammalian target of rapamycin (mTOR) and insulin signaling pathways (Table V). This intricate network of interplay between these highly tumorigenic proteins warrants further 
Table III. Upstream regulators predicted to be either activated (in addition to the above top 5 upstream regulators), or inhibited in the IMR-32 compared to the SK-N-SH cells based on the statistically significant over- or underexpression of molecules within the IPA-derived dataset.
Predicted to be activated
MYC, ESRRA, MYCN, INSR, HIST1HIT, HIST1H1A, HIF1A, EIF4E, EIF4G1, SREBF2, ANGPT2, FLI1, IL3, SREBF1, SCAP, RUVBL1, SP1, CD4OLG, EPAS1, KITLG, ADORA2A, PGR, KAT5, PSEN1
Predicted to be inhibited

\author{
ALYREF, ANK2, ATG7, CCDC88A, CHTOP , CPSF1, CPSF2, CPSF3, CSTF1, DDX39A, \\ $D D X 39 B, D E N R$
}

Table IV. Functional annotation of upstream regulators of the overexpressed proteins in the IMR-32 cells and the signaling pathways they are affiliate with $^{\mathrm{a}}$.

\begin{tabular}{|c|c|c|}
\hline Pathways & $\begin{array}{l}\text { Adjusted } \\
\text { P-value }\end{array}$ & Genes overexpressed \\
\hline SREBP signaling_WP1982 & $8.04 \mathrm{E}-05$ & SREBF 1, SP1, SCAP, SREBF2 \\
\hline Adipogenesis_WP236 & 4.00E-04 & SREBF 1, EPAS1, SP1, HIF $1 A$ \\
\hline Hematopoietic stem cell differentiation & $4.55 \mathrm{E}-04$ & $I L 3, K I T L G, F L I 1$ \\
\hline AGE/RAGE pathway_WP2324 & $9.50 \mathrm{E}-04$ & SPl, INSR, HIF $1 A$ \\
\hline SREBF and miR-33 in cholesterol and lipid homeostasis_WP2011 & $2.79 \mathrm{E}-03$ & $S R E B F 1, S R E B F 2$ \\
\hline Mitochondrial gene expression_WP391 & $3.11 \mathrm{E}-03$ & ESRRA, SPI \\
\hline Nuclear receptors_WP170 & $9.47 \mathrm{E}-03$ & ESRRA, PGR \\
\hline Integrated pancreatic cancer pathway_WP2377 & $1.20 \mathrm{E}-02$ & $I L 3, S P 1, M Y C$ \\
\hline Differentiation pathway_WP2848 & $1.20 \mathrm{E}-02$ & $I L 3, K I T L G$ \\
\hline Translation factors_WP107 & $1.20 \mathrm{E}-02$ & $E I F 4 E, E I F 4 G 1$ \\
\hline Notch signaling pathway_WP61 & $1.67 \mathrm{E}-02$ & $M Y C, H I F 1 A$ \\
\hline Rac1/Pak1/p38/MMP-2 pathway_WP3303 & $1.84 \mathrm{E}-02$ & $A N P G P T 2, M Y C$ \\
\hline AMPK signaling_WP1403 & $1.85 \mathrm{E}-02$ & SREBF 1, INSR \\
\hline Leptin signaling pathway_WP2034 & $2.08 \mathrm{E}-02$ & $S P 1, E I F 4 E$ \\
\hline Androgen receptor signaling pathway_WP138 & $2.78 \mathrm{E}-02$ & $K A T 5, S P 1$ \\
\hline DNA damage response (only ATM dependent)_WP710 & $4.08 \mathrm{E}-02$ & $M Y C, I N S R$ \\
\hline miR-148/miR-31/FIH1/HIF1? - Notch signaling in glioblastoma_WP3593 & $5.00 \mathrm{E}-02$ & HIF $1 A$ \\
\hline
\end{tabular}

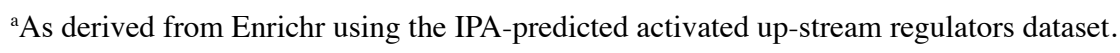

investigation, particularly in pre-clinical, animal models, whereby multiple targeting of more than one of these players may yield beneficial, antitumor effects and improve therapeutic outcomes.

Novel pathways link the MYCN-affected proteins in the IMR-32 cells to cancer malignancy. In addition to the above-mentioned pathways, when we combined only $M Y C$, $M Y C N$ and our validated targets in the STRING protein network analysis (Fig. 3A), we found very strong interactions between $M Y C, M Y C N, B I R C 5$ and $H M G A l$ with Aurora kinase $(A U R K) A / B$, cyclin-dependent kinase $1(C D K 1)$, cell division cycle associated $8(C D C A 8)$ and INCENP. These players were mapped to cellular functions highly affiliated with mitosis and cellular division and proliferation (Table VI). Lastly, L1-CAM focused network analysis revealed its strong interaction with neural cell adhesion molecule 1 (NCAM1), neurocan (NCAN), ezrin (EZR), RDX, ANK1, ANK2, contactin 2 (CNTN2), neuropilin $1(N R P 1)$, epidermal growth factor receptor $(E G F R)$ and
RAN binding protein 9 (RANBP9) (Fig. 3B), most of which drive angiogenic and migratory processes to fuel cellular invasion, migration and metastatic spread.

Transcriptional KD experiments reveal interplay between tumorigenic proteins upregulated in IMR-32 cells. We then aimed to transcriptionally KD the protein expression of these molecules and determine the effects of this KD on cellular biofunction. Additionally, we wished to determine whether the downregulation of one protein would affect the expression level of the other targets, thereby implicating a potential interplay between the proteins. Using transient siRNA transfection, we successfully downregulated the protein expression (Fig. 4A) of MYCN ( 85\%), HMGAl ( 60\%), FABP5 ( 60\%) and L1-CAM $(\sim 80 \%)$ as determined by western blot analysis at $48 \mathrm{~h}$ after siRNA transfection (Fig. 4B). Of note, L1-CAM, HMGAl and $F A B P 5$ transcriptional KD led to the significant concomitant downregulation of MYCN protein expression by $\sim 80,90$ and $75 \%$, respectively (Fig. 5A). In addition, $M Y C N$ transcriptional 
Table V. Common tumorigenic pathways that MYCN, BIRC5 and the activated upstream regulators mapped to.

\begin{tabular}{|c|c|c|c|c|}
\hline $\begin{array}{l}\text { Pathway } \\
\text { ID no. }\end{array}$ & $\begin{array}{c}\text { Pathway } \\
\text { description }\end{array}$ & $\begin{array}{l}\text { Observed } \\
\text { gene count }\end{array}$ & $\begin{array}{c}\text { False } \\
\text { discovery } \\
\text { rate }\end{array}$ & $\begin{array}{l}\text { Matching proteins in } \\
\text { your network (labels) }\end{array}$ \\
\hline 4151 & PI3K-Akt signaling pathway & 6 & $1.26 \mathrm{E}-05$ & ANGPT2, EIF4E, IL3, INSR, KITLG, MYC \\
\hline 5202 & Transcriptional misregulation in cancer & 5 & $1.26 \mathrm{E}-05$ & $F L I 1, I L 3, M Y C, M Y C N, S P 1$ \\
\hline 4066 & HIF-1 signaling pathway & 4 & $7.58 \mathrm{E}-05$ & ANGPT2, EIF4E, HIF1A, INSR \\
\hline 5200 & Pathways in cancer & 5 & $5.02 \mathrm{E}-03$ & BIRC5, HIF 1A, KITLG, MYC, EPAS1 \\
\hline 4910 & Insulin signaling pathway & 3 & $6.48 \mathrm{E}-03$ & EIF4E, INSR, SREBFI \\
\hline 4015 & Rap1 signaling pathway & 4 & $1.95 \mathrm{E}-02$ & ADORA2A, ANGPT2, INSR, KITLG \\
\hline 4014 & Ras signaling pathway & 3 & $2.05 \mathrm{E}-02$ & ANGPT2, INSR, KITLG \\
\hline 4310 & Wnt signaling pathway & 3 & $1.84 \mathrm{E}-02$ & $M Y C, P S E N 1, R U V B L 1$ \\
\hline 4150 & mTOR signaling pathway & 2 & $2.67 \mathrm{E}-02$ & EIF4E, HIF $1 A$ \\
\hline 5210 & Colorectal cancer & 2 & $2.67 \mathrm{E}-02$ & BIRC5, MYC \\
\hline 4350 & TGF- $\beta$ signaling pathway & 2 & 4.08E-02 & $M Y C, S P 1$ \\
\hline 4640 & Hematopoietic cell lineage & 2 & $4.51 \mathrm{E}-02$ & $I L 3, K I T L G$ \\
\hline
\end{tabular}

When we combined the predicted activated upstream regulators and MYCN in the STRING protein network analysis, the common pathways identified were highly tumorigenic, including PI3K-Akt, transcriptional misregulation in cancer, pathways in cancer, HIF-1, Wnt, Rap1, Ras, mTOR, TGF- $\beta$ and insulin signaling pathways.
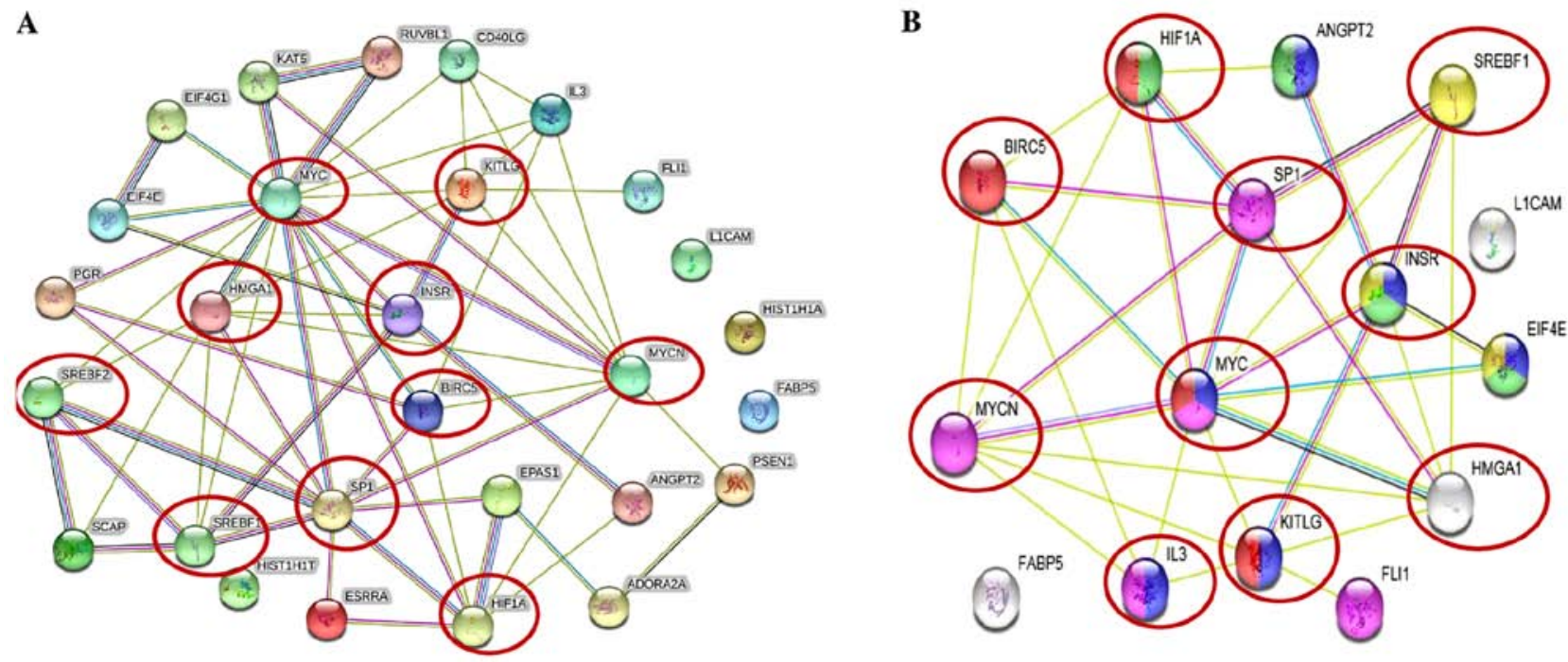

Figure 2. Tumorigenic proteins significantly upregulated in the IMR-32 cells mapped to the MYCN proto-oncogene, bHLH transcription factor (MYCN) pathway. (A) STRING pathway analysis revealed interactions between molecules of activated upstream regulators in IMR-32 cells as predicted by IPA. Of importance are the various proteins with hubs (multiple edges, red circles), including Sp1 transcription factor (SP1), MYC, MYCN, hypoxia-inducible factor-1 $\alpha(\mathrm{HIF}-1 \alpha)$, high mobility group protein A1 (HMGA1), INSR, KIT ligand (KITLG), sterol regulatory element binding transcription factor 2 (SREBF2) and SREBF1. (B) STRING pathway analysis also focused on the strong interactions between the activated upstream regulators which HMGA1, MYCN and BIRC5 mapped to. Of particular interest are the hubs, including MYCN, MYC, SP1, HIF-1 $\alpha$, SREBF1, BIRC5, HMGA1 and INSR that affiliated with one or more of our validated targets.

KD led to the significant concomitant downregulation of L1-CAM, HMGAl and FABP5 protein expression by $\sim 77,75$ and 70, respectively (Fig. 5B). Moreover, the combined transcriptional KD of L1-CAM and FABP5 led to the significant concomitant downregulation of $H M G A 1$ protein expression by $\sim 70 \%$ (Fig. 5C), while survivin protein expression was abrogated following the transcriptional $\mathrm{KD}$ of $M Y C N, H M G A I$ and FABP5 (Fig. 5D). This interplay between these tumorigenic proteins is extremely interesting and warrants further investigation into the mechanisms utilized by this network to drive cancerous progression and malignant, treatment-evasive recurrence in high-risk, $M Y C N$-amplified pediatric neuroblastomas.

Transcriptional KD of tumorigenic proteins inhibits the proliferation and migration of IMR-32 cells. To determine the cellular bio-functional effects of the transcriptional downregulation of our protein targets, we examined the rate of proliferation of the IMR-32 cells over 5 days following the transcriptional KD of these tumorigenic proteins. We observed 
A

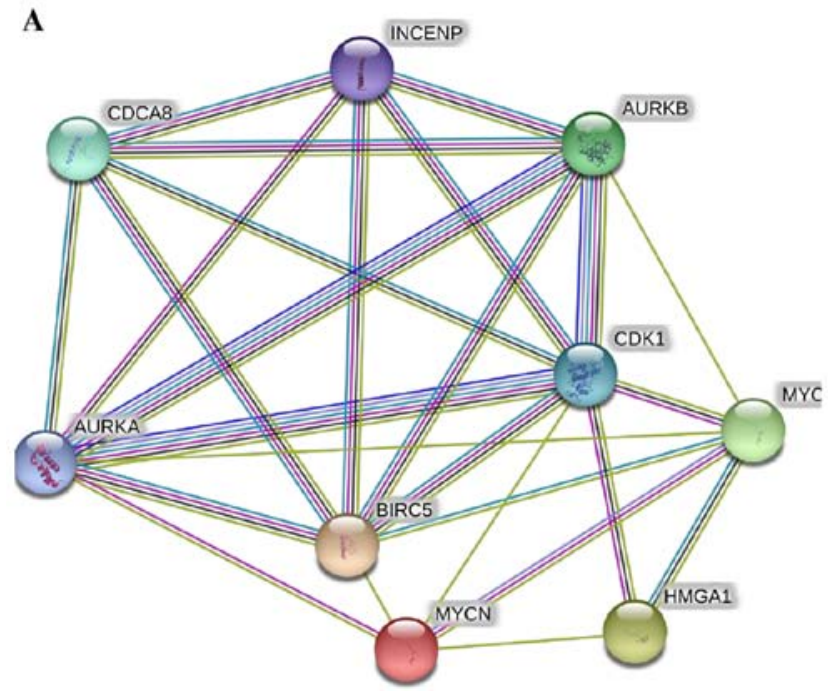

B

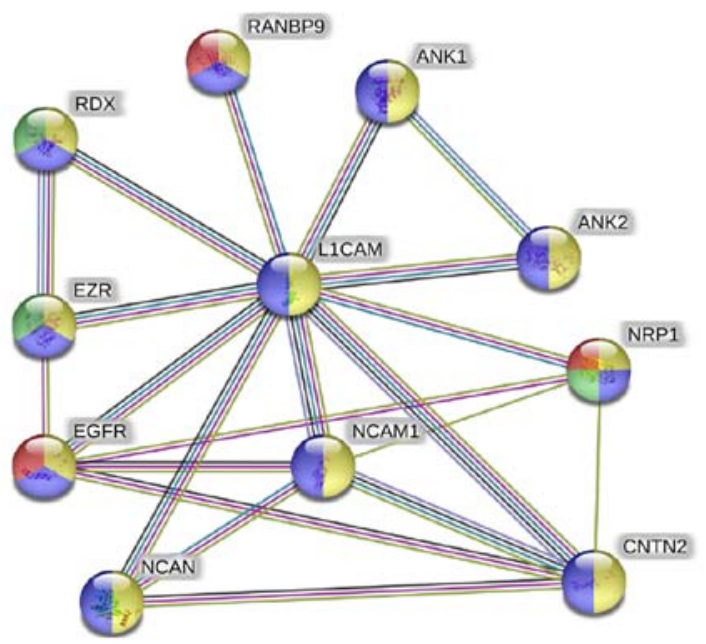

Figure 3. Novel pathways link the MYCN proto-oncogene, bHLH transcription factor (MYCN)-affected proteins in IMR-32 cells to cancer malignancy. (A) STRING pathway analysis revealed very strong interactions between MYCN, BIRC5, high mobility group protein A1 (HMGA1) and the cellular mitosis and proliferation players AURKA/B, cyclin-dependent kinase 1 (CDK1), CDCA8 and INCENP; (B) whereas L1-cell adhesion molecule (L1-CAM) showed very strong interactions with neural cell adhesion molecule 1 (NCAM1), neuropilin-1 (NRP1), NCAN, contactin 2 (CNTN2), RANBP1 and epidermal growth factor receptor (EGFR) among others most of which are angiogenic markers.

$\mathbf{A}$
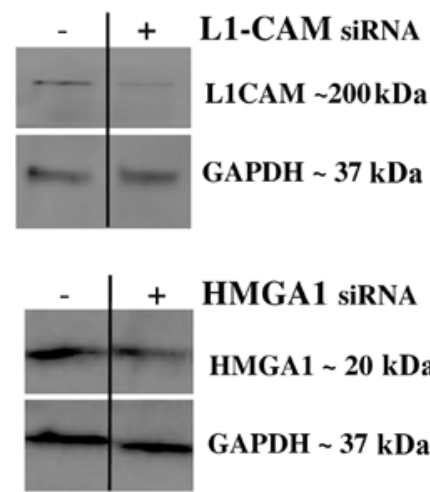

HMGA1 siRNA

HMGA1 $20 \mathrm{kDa}$

GAPDH 37 kDa

B

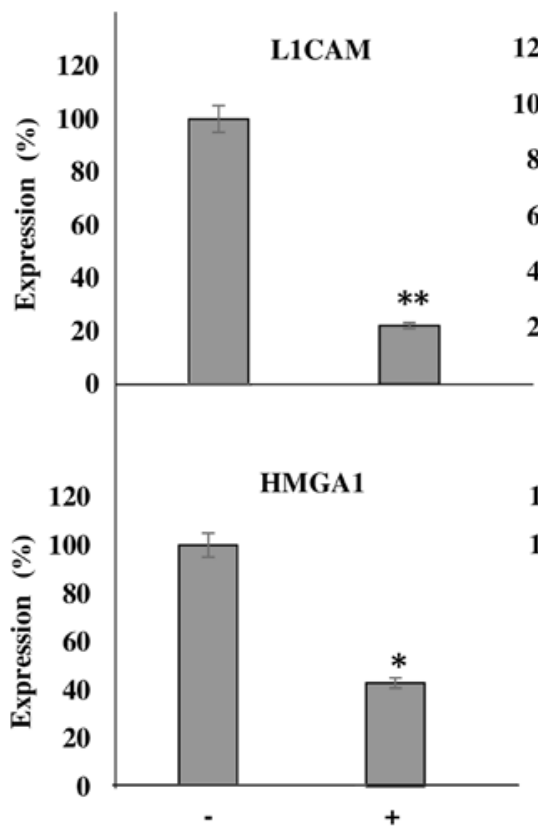

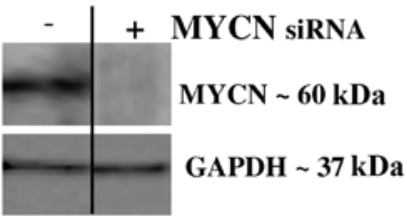
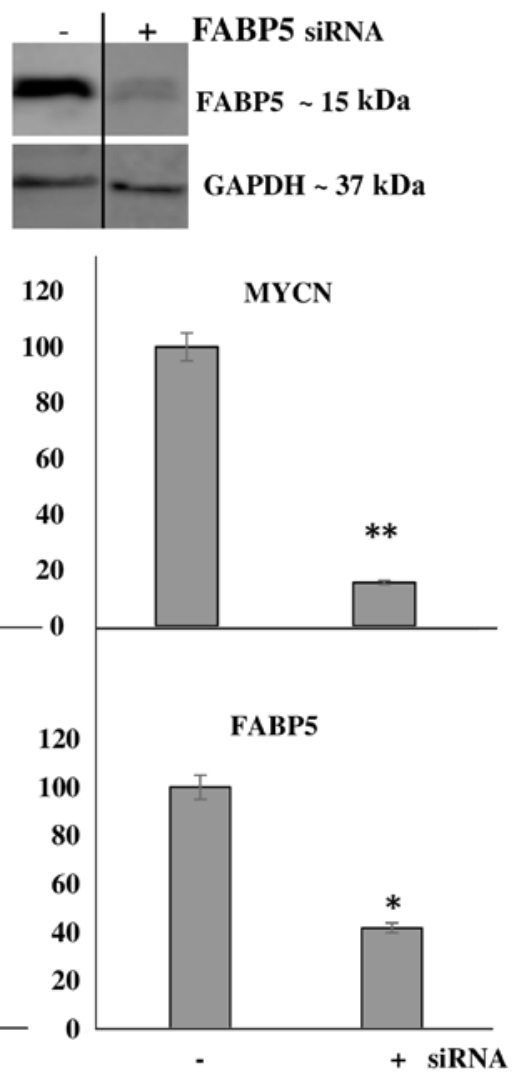

Figure 4. The transcriptional knockdown of tumorigenic proteins significantly decreases protein expression. (A) Transient transfection with siRNA targeting L1-cell adhesion molecule (L1-CAM), high mobility group protein A1 (HMGA1), MYCN proto-oncogene, bHLH transcription factor (MYCN) and fatty-acid binding protein 5 (FABP5) abrogated their protein expression. (B) Densitometric analysis of multiple experimental repeats revealed a significant decrease in the expression of the said proteins compared to control siRNA-transfected cells. Experiments were run in triplicate and repeated $>3$ times. Results represent the means $\pm \mathrm{SEM} ;{ }^{*} \mathrm{P}<0.05$ and ${ }^{* *} \mathrm{P}<0.001$. 
A
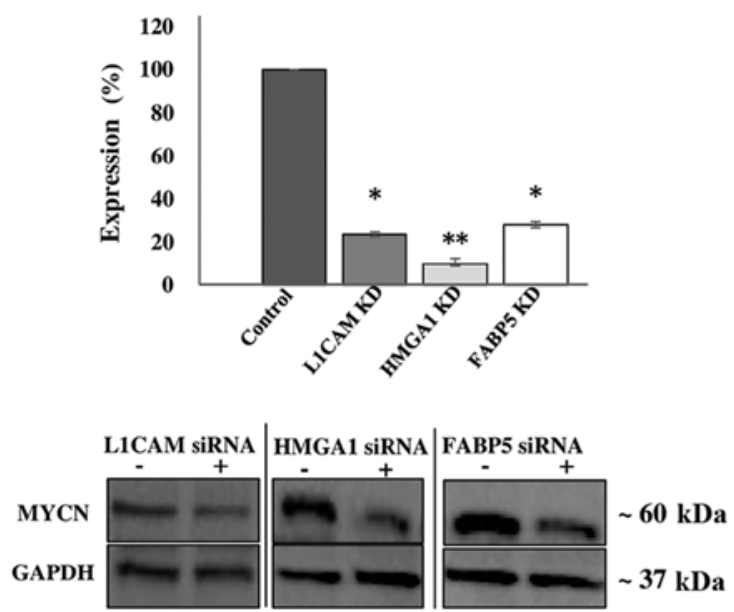

C

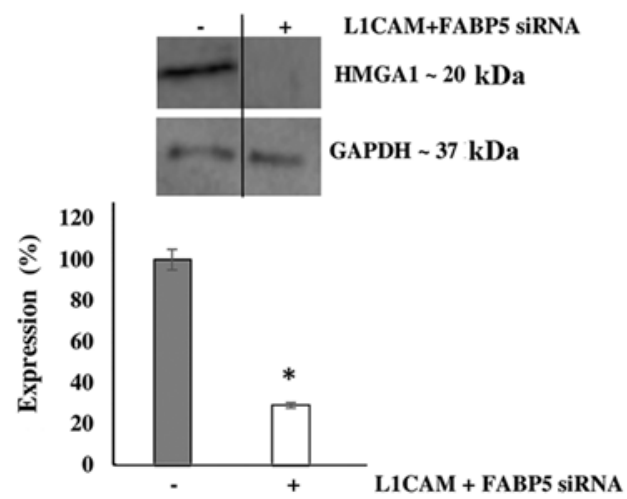

B

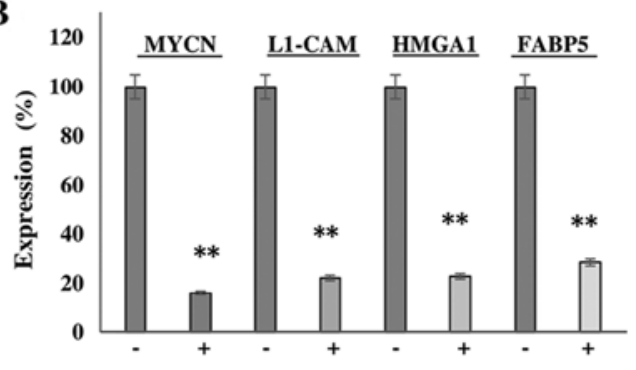

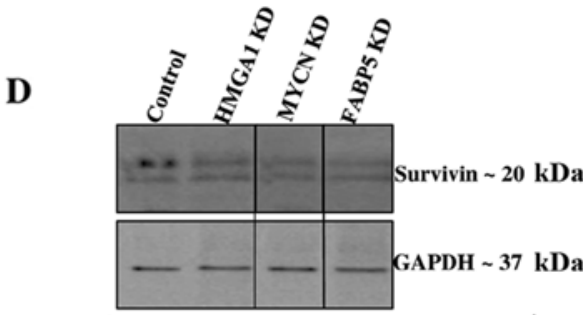
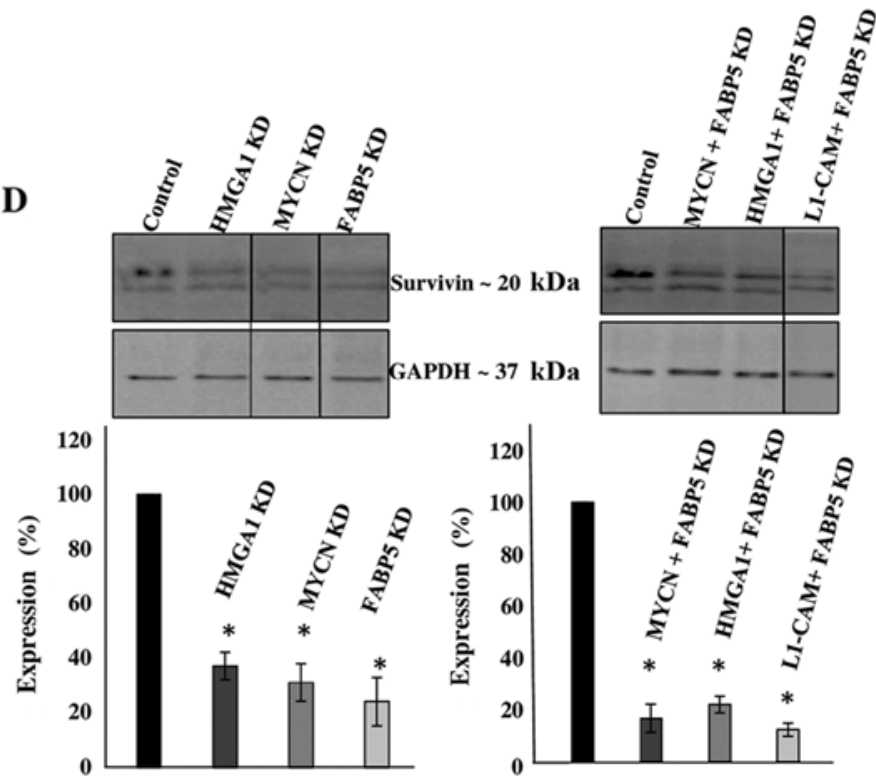

Figure 5. Transcriptional knockdown experiments reveal an interplay between tumorigenic proteins. (A) Western blot analysis revealed a concomitant significant downregulation of MYCN proto-oncogene, bHLH transcription factor (MYCN) protein expression following the knockdown of L1-cell adhesion molecule (L1-CAM), high mobility group protein A1 (HMGA1) and fatty-acid binding protein 5 (FABP5) by siRNA in the IMR-32 cells compared to the controls. (B) Conversely, MYCN knockdown by siRNA led to the concomitant significant downregulation of L1-CAM, HMGA1 and FABP5 protein expression, whereas (C) the combined knockdown of L1-CAM and FABP5 by siRNA led to the concomitant significant downregulation of HMGA1 protein expression. (D) MYCN, HMGA1 and FABP5 knockdown and the combined dual-target knockdown led to the concomitant downregulation of survivin protein expression. Non-adjacent bands of western blot experiments were re-aligned side by side to increase the clarity of the presented data and designated by a straight vertical line. Experiments were run in triplicate and repeated $>3$ times. Results represent the means $\pm \mathrm{SEM} ;{ }^{*} \mathrm{P}<0.05$ and ${ }^{* *} \mathrm{P}<0.01$.

no significant differences in the rate of the proliferation of IMR-32 cells at 0 and $24 \mathrm{~h}$ following the transcriptional KD of all the above-mentioned siRNA-targeted, tumorigenic proteins compared to the controls. However, there was a statistically significant reduction in the rate of cellular proliferation between the MYCN, L1-CAM, HMGA1 and FABP5 siRNA-transfected cells and the controls at 48, 72 and $96 \mathrm{~h}$ post-siRNA transfection (Fig. 6A), implicating the role of these proteins in highly proliferative signaling pathways. The rate of the proliferation of cells targeted with double-target siRNA transfection $(M Y C N+L 1-C A M, M Y C N+H M G A 1, M Y C N+F A B P 5$, $H M G A 1+L 1-C A M, H M G A 1+F A B P 5$ and FAB5 + L1-CAM) was also significantly decreased from 48 to $96 \mathrm{~h}$ post-transfection compared to the controls (Fig. 6B). Double-target siRNA transfection did not exert an additive effect on the rate of cell proliferation compared to the single-target siRNA-transfected cells (data not shown); thus, we speculate on the possible redundancy of the proliferative signaling pathways of these proteins. We then sought to examine the effects of FABP5 and
HMGAl transcriptional KD on the migration of IMR-32 cells, since L1-CAM (25) and MYCN $(26,27)$ have been previously reported to affect neuroblastoma cell migration. Using the 'wound healing' scratch assay (Fig. 6C) we observed a significant decrease in the migratory capacity of the IMR-32 cells subjected to FABP5 or HMGAl transcriptional KD at $24 \mathrm{~h}$ after 'wound induction' (Fig. 6D).

Transcriptional KD of FABP5 and MYCN induces the early apoptosis of IMR-32 cells. Lastly we wished to determine whether the transcriptional KD of the tumorigenic proteins would affect the rate of apoptosis of IMR-32 cells. The late apoptotic rate was not observed to differ significantly between the controls and siRNA-transfected cells of any target at $48 \mathrm{~h}$ following transcriptional KD (Fig. 7A). However, early apoptosis was significantly higher in the cells subjected to FABP5 and MYCN transcriptional siRNA KD at $48 \mathrm{~h}$, as determined by Annexin V/PI staining and FACS analysis (Fig. 7B). This was confirmed by immunofluorescence staining of the cells 
A
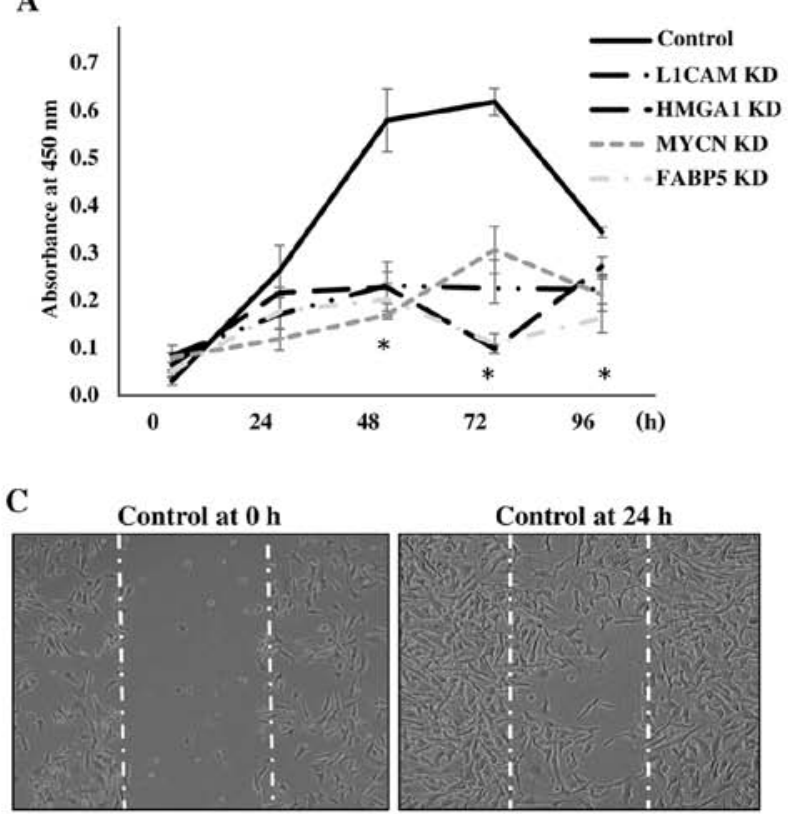

HMGA1 KD at $24 \mathrm{~h}$

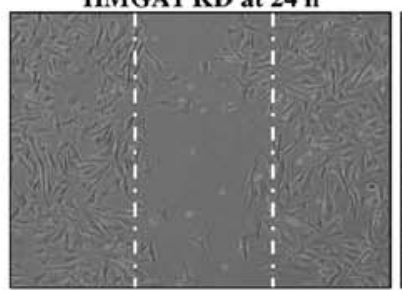

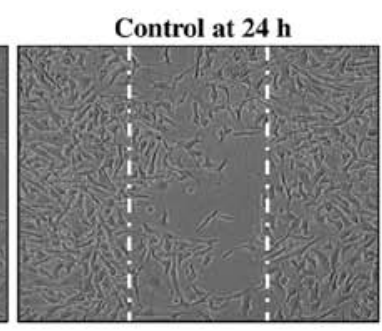

FABP5 KD at $24 \mathrm{~h}$

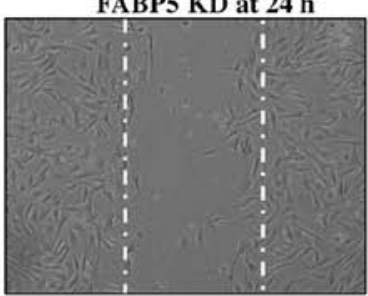

B

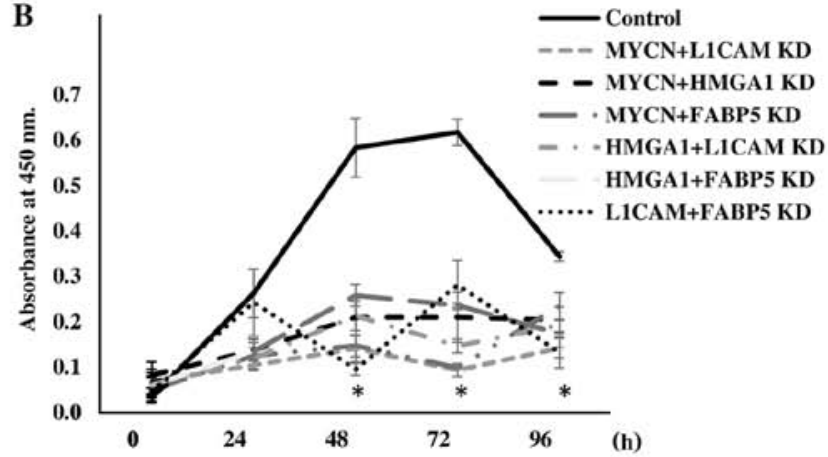

D

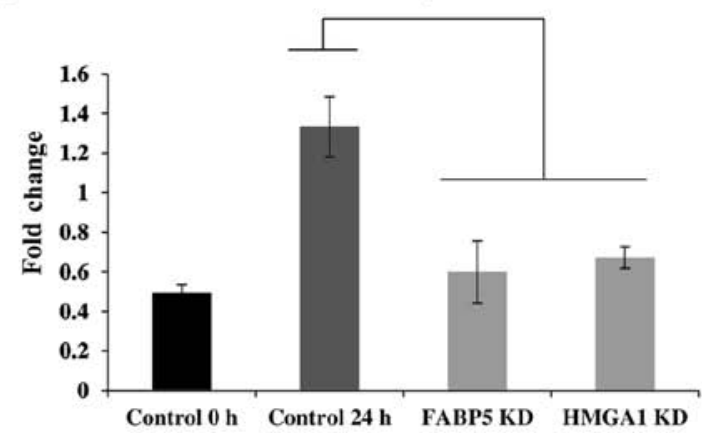

Figure 6. Transcriptional knockdown of tumorigenic proteins inhibits the proliferation and migration of IMR-32 cells. (A) Transient siRNA transfection and knockdown of MYCN proto-oncogene, bHLH transcription factor (MYCN), L1-cell adhesion molecule (L1-CAM), high mobility group protein A1 (HMGA1) and fatty-acid binding protein 5 (FABP5) protein expression led to a significant decrease in IMR-32 cell proliferation from 48 -96 $\mathrm{h}$ compared to the controls, as determined using a WST-1 cell proliferation assay. (B) Double-siRNA targeted knockdown (MYCN + L1-CAM, MYCN + HMGA1, MYCN + FABP5, L1-CAM + HMGA1, L1-CAM + FABP5 and HMGA1 + FABP5) also led to significant decrease in the IMR-32 cellular proliferation rate from 48-96 $\mathrm{h}$ compared to the controls. (C) Representative images of 'wound closure' illustrate a reduction in the migratory capacity of the IMR-32 cells subjected to FABP5 and HMGA1 siRNA knockdown. (D) The average area of 'wound closure' in multiple random fields, measured using AxioVision Systems software, revealed a statistically significant decrease in IMR-32 cell migration compared to the controls. Experiments were run in triplicate and repeated $>3$ times. Results represent the means $\pm \mathrm{SEM} ;{ }^{*} \mathrm{P}<0.05$.

with Annexin V and PI (Fig. 7C). Perhaps a difference in the rate of late apoptosis would be observed had we conducted the apoptosis assay at 72 or $96 \mathrm{~h}$ post-transcriptional KD.

\section{Discussion}

Neuroblastoma is a devastating childhood cancer with a dismal prognosis if presented in the high-risk group at diagnosis. IMR-32 is a $M Y C N$-amplified, highly malignant human neuroblastoma cell line. On the contrary, SK-N-SH, while a metastatic human neuroblastoma cell line derived from an epithelial origin (28), is non- $M Y C N$-amplified (29), and hence, is considered less invasive than the IMR-32 cells and a good cell line to use in comparison to IMR-32. In addition to the well-established pathways known to affiliate with $M Y C N$ in tumorigenic processes, we sought to discover whether other tumorigenic proteins and/or pathways are also 'accomplices' of the main 'culprit' $M Y C N$, in its pursuit of cancerous-progression, malignancy, anti-apoptosis and resistance to treatment in high-risk neuroblastoma.

Our preliminary analysis of the proteomic signatures in the $M Y C N$-amplified IMR-32 compared to the non- $M Y C N$-amplified SK-N-SH cells revealed some noteworthy, upregulated tumorigenic proteins in the IMR-32 compared to the SK-N-SH cells. Enrichr mapped these proteins to highly cancerous pathways, including leptin signaling, AGE/RAGE signaling, AMPK signaling, Notch, SREBP and Racl/Pakl/p38/MMP-2 signaling pathways, among others. The leptin signaling pathway is highly affiliated with cancer migration and invasion (30), whereas SREBP, AGE/RAGE, Notch, Rac and $A M P K$ have all been implicated in the tumorigenesis of various nervous system cancers, as well as other solid tumors (19-24). IMR-32 cells represent a highly malignant, invasive, treatment-resistant form of neuroblastoma and the identification of these activated pathways within them has shed some light on the understanding of their malignant mechanisms.

Of the SILAC identified upregulated proteins, we selected to verify with western blot analysis, the protein expression of several that mapped to more than one activated tumorigenic pathways including, L1-CAM (mapped to upstream regulators APP and HIF-1 $\alpha$ ), HMGAl (mapped to activated upstream regulators $M Y C, A P P, E 2 F 1, M Y C N$ and $S P 1$ ), FABP5 (mapped to activated upstream regulators $M Y C, S R E B F 2, S R E B F 1$ and 

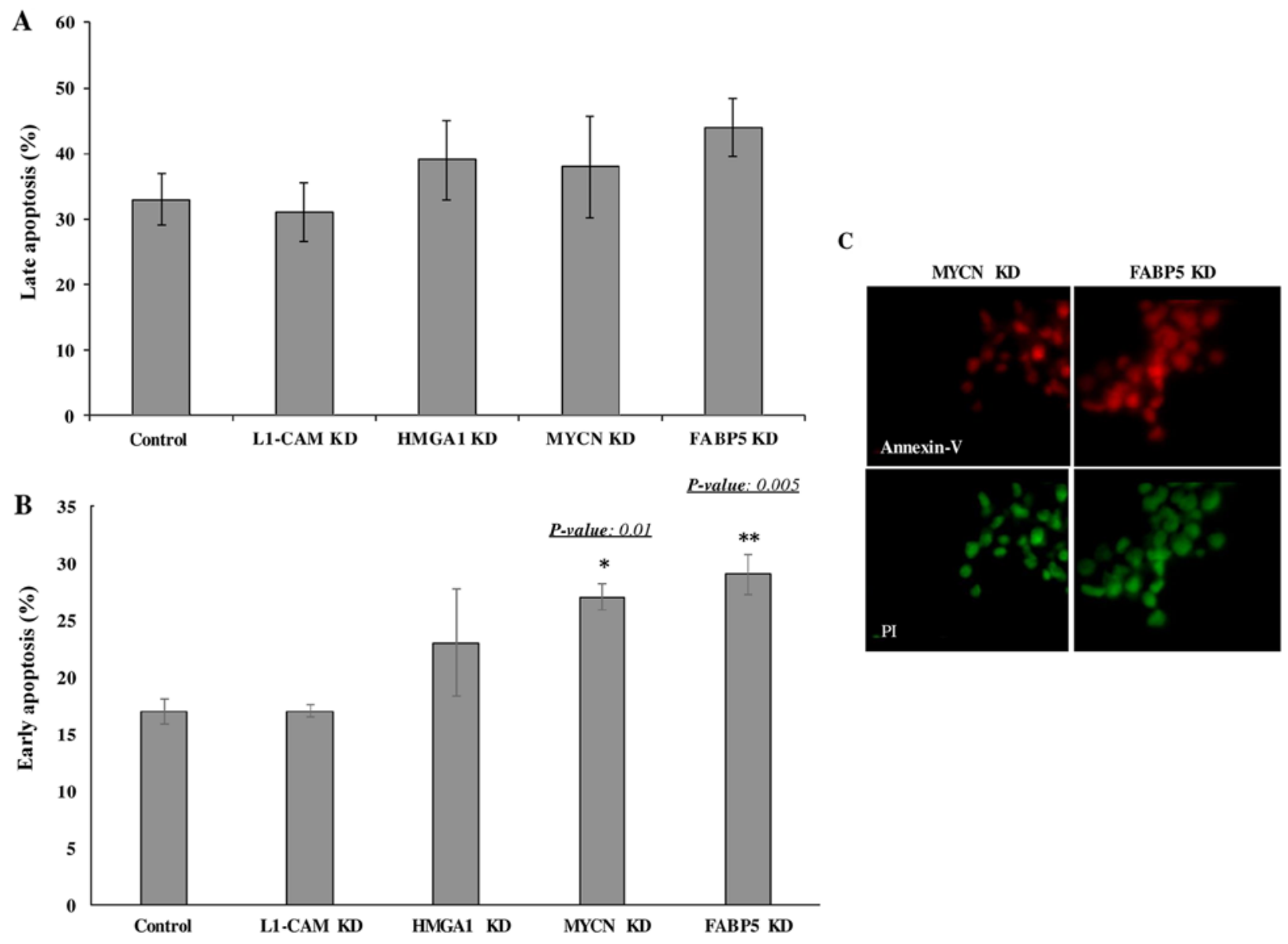

Figure 7. Transcriptional knockdown of MYCN proto-oncogene, bHLH transcription factor (MYCN) and fatty-acid binding protein 5 (FABP5) induces cellular apoptosis of IMR-32 cells. (A) The rate of late cellular apoptosis between MYCN, L1-cell adhesion molecule (L1-CAM), high mobility group protein A1 (HMGA1) and FABP5 siRNA-transfected and control IMR-32 cells did not differ significantly at $48 \mathrm{~h}$ post-transfection as determined using an Annexin V/propidium iodide (PI) cell apoptosis assay and flow cytometry analysis. (B) The rate of early apoptosis in MYCN and FABP5 siRNA-transfected IMR-32 cells was significantly higher compared to controls ( $\sim 27$ and $\sim 29 \%$ compared to $\sim 17 \%$, respectively) at $48 \mathrm{~h}$ post-transfection. (C) Fluorescence microscopy images of MYCN and FABP5 siRNA-transfected cells stained with Annexin V (red) and PI (green) at $48 \mathrm{~h}$ post-transfection. Experiments were run in triplicates and repeated $>3$ times. Results represent the mean \pm SEM.

$K I T L G$ ) and survivin or BIRC5 (mapped to activated upstream regulators $I L 3, M Y C N$ and $M Y C$ ) to determine their interaction with $M Y C N$ in the IMR-32 cells. As shown in Table V, there is intriguing overlap between these upstream regulators in highly tumorigenic pathways including, pathways in cancer, transcriptional misregulation in cancer, PI3K/AKT, Ras, Rapl, $T G F-\beta, H I F-1 \alpha, W n t$, insulin and $m T O R$ signaling pathways. The $m T O R$ pathway, one of the most potent signaling pathways involved in cellular proliferation and protein synthesis, is highly activated in $M Y C N$-amplified cell lines (31). Moreover, when MYCN-amplified IMR-32 cells are treated with SU11657 (SUGEN), a selective multi-targeted tyrosine kinase inhibitor with antitumor and anti-angiogenic activity, their growth is significantly inhibited (32).

L1-CAM is a neural cell adhesion molecule L1 found to be expressed in numerous tumors, such as neuroblastomas (25), glioblastomas, melanomas, lymphomas, as well as breast, colon, small cell lung carcinomas and gastrointestinal stromal tumors $(33,34)$. L1-CAM plays a significant role in tumor progression and metastatic behavior (35), and the expression profile analysis in multiple human tumors has identified L1-CAM as a molecular marker for differential diagnosis and targeted therapy (36). Of note, various studies have recently implicated $L 1-C A M$ in cancer stem-cell maintenance and propagation (37), the activation of DNA damage checkpoint response that confers resistant to radiation therapy (38) and cancer cell migration and malignancy (39) in glioblastoma and neuroblastoma (40). Moreover, the strong interactions between L1-CAM and EGFR, RANBP9 and NCAM1 (which affiliates with $T G F-\beta$ ) (41) and $N R P I$ (Fig. 3), may enhance IMR-32 cell invasion and metastasis via an angiogenesis-driven, migratory mechanism.

HMGAl belongs to a large family of non-histone DNA-binding factors that play important architectural functions in the organization of active chromatin (42). In addition to its role in physiologic processes, a deregulated HMGAl expression is described in most tumors of epithelial and mesenchymal origin, and is considered a hallmark of cancer (43). Particularly, higher levels of $H M G A l$ expression are associated with more malignant and metastatic phenotypes in epithelial cancers $(44,45)$. Furthermore, HMGAl regulation may be controlled by $M Y C N$, which upregulates HMGA1 expression in neuroblastoma cells and in neuroblastoma-like tumors arising in MYCN transgenic mice. Moreover, HMGAl has been shown to be a direct $M Y C N$ transcriptional target, suggesting that HMGAl is a biologically relevant $M Y C N$ target gene (46). 
Table VI. Common tumorigenic pathways that MYC and our validated targets (BIRC5, HMGA1 and MYCN) mapped to.

\begin{tabular}{|c|c|c|c|c|}
\hline $\begin{array}{l}\text { Pathway } \\
\text { ID no. }\end{array}$ & $\begin{array}{l}\text { Pathway } \\
\text { description }\end{array}$ & $\begin{array}{l}\text { Observed } \\
\text { gene count }\end{array}$ & $\begin{array}{c}\text { False } \\
\text { discovery } \\
\text { rate }\end{array}$ & $\begin{array}{l}\text { Matching proteins in } \\
\text { your network (labels) }\end{array}$ \\
\hline GO.0051301 & Cell division & 6 & 0.000118 & $\begin{array}{l}\text { AURKA, AURKB, BIRC5, CDCA8, } \\
C D K 1, \text { INCENP }\end{array}$ \\
\hline GO.0007067 & Mitotic nuclear division & 5 & 0.000834 & AURKB, BIRC5, CDCA8, CDK1, INCENP \\
\hline GO.0007052 & Mitotic spindle organization & 3 & 0.0017 & AURKA, AURKB, BIRC5 \\
\hline GO.0007059 & Chromosome segregation & 4 & 0.0017 & AURKB , BIRC5, CDCA8, INCENP \\
\hline GO.0043146 & Spindle stabilization & 2 & 0.00178 & $A U R K A, A U R K B$ \\
\hline GO.0051225 & Spindle assembly & 3 & 0.00178 & AURKA, AURKB, BIRC5 \\
\hline GO.0051302 & Regulation of cell division & 4 & 0.00382 & AURKA, AURKB, BIRC5, MYC \\
\hline GO.0007264 & $\begin{array}{l}\text { Small GTPase-mediated } \\
\text { signal transduction }\end{array}$ & 5 & 0.00405 & AURKB , BIRC5, CDCA8, CDK1, INCENP \\
\hline GO.0000910 & Cytokinesis & 3 & 0.00568 & AURKB, BIRC5, INCENP \\
\hline GO.0031145 & $\begin{array}{l}\text { Anaphase-promoting } \\
\text { complex-dependent } \\
\text { proteasomal ubiquitin-dependent } \\
\text { protein catabolic process }\end{array}$ & 3 & 0.00568 & $A U R K A, A U R K B, C D K 1$ \\
\hline GO.0010941 & Regulation of cell death & 6 & 0.00604 & $\begin{array}{l}A U R K A, A U R K B, B I R C 5, C D K 1, \\
M Y C, M Y C N\end{array}$ \\
\hline GO.0006468 & Protein phosphorylation & 5 & 0.00685 & AURKA, AURKB, BIRC5, CDK1, MYC \\
\hline GO.0018105 & Peptidyl-serine phosphorylation & 3 & 0.00685 & $A U R K A, A U R K B, C D K 1$ \\
\hline GO.0034501 & Protein localization to kinetochore & 2 & 0.00685 & $A U R K B, C D K 1$ \\
\hline GO.0035404 & Histone-serine phosphorylation & 2 & 0.00685 & $A U R K A, A U R K B$ \\
\hline GO.0043066 & Negative regulation of apoptotic process & 5 & 0.00685 & AURKA, AURKB, BIRC5, CDK1, MYC \\
\hline GO.0051276 & Chromosome organization & 5 & 0.00736 & $A U R K A, A U R K B, C D C A 8, H M G A 1, M Y C$ \\
\hline GO.0006996 & Organelle organization & 7 & 0.00837 & $\begin{array}{l}\text { AURKB, BIRC5, CDCA8, CDK1, HMGA1, } \\
\text { INCENP, MYC }\end{array}$ \\
\hline GO.0051781 & Positive regulation of cell division & 3 & 0.0103 & $A U R K A, A U R K B, B I R C 5$ \\
\hline GO.0035556 & Intracellular signal transduction & 6 & 0.0104 & $\begin{array}{l}\text { AURKB , BIRC5, CDCA8, CDK1, } \\
\text { INCENP, MYC }\end{array}$ \\
\hline GO.0000086 & $\mathrm{G} 2 / \mathrm{M}$ transition of mitotic cell cycle & 3 & 0.0122 & $A U R K A, B I R C 5, C D K 1$ \\
\hline GO.0022402 & Cell cycle process & 5 & 0.0122 & AURKB, BIRC5, CDCA8, INCENP, MYC \\
\hline GO.1902589 & Single-organism organelle organization & 6 & 0.0131 & $\begin{array}{l}A U R K B, B I R C 5, C D C A 8, C D K 1, \\
H M G A 1, I N C E N P\end{array}$ \\
\hline GO.0033043 & Regulation of organelle organization & 5 & 0.0134 & AURKA, AURKB, BIRC5, HMGA1, MYC \\
\hline GO.0090307 & Mitotic spindle assembly & 2 & 0.0136 & $A U R K B, B I R C 5$ \\
\hline GO.0016568 & Chromatin modification & 4 & 0.0151 & $A U R K A, A U R K B, H M G A 1, M Y C$ \\
\hline GO.0007049 & Cell cycle & 5 & 0.026 & AURKB, BIRC5, CDCA8, INCENP, MYC \\
\hline GO.0000075 & Cell cycle checkpoint & 3 & 0.0275 & $A U R K B, B I R C 5, C D K 1$ \\
\hline GO.0002053 & $\begin{array}{l}\text { Positive regulation of mesenchymal } \\
\text { cell proliferation }\end{array}$ & 2 & 0.0275 & $M Y C, M Y C N$ \\
\hline GO.0007098 & Centrosome cycle & 2 & 0.0275 & $A U R K A, C D K 1$ \\
\hline GO.0090068 & Positive regulation of cell cycle process & 3 & 0.0338 & AURKA, AURKB, BIRC5 \\
\hline GO.0031577 & Spindle checkpoint & 2 & 0.0342 & $A U R K B, B I R C 5$ \\
\hline GO.1903047 & Mitotic cell cycle process & 4 & 0.0372 & AURKB, BIRC5, CDCA8, INCENP \\
\hline GO.0030162 & Regulation of proteolysis & 4 & 0.0399 & AURKA, BIRC5, CDK1, MYC \\
\hline GO.0045840 & $\begin{array}{l}\text { Positive regulation of mitotic } \\
\text { nuclear division }\end{array}$ & 2 & 0.0412 & AURKA, BIRC5 \\
\hline GO.0051303 & $\begin{array}{l}\text { Establishment of } \\
\text { chromosome localization }\end{array}$ & 2 & 0.0434 & BIRC5, CDCA8 \\
\hline GO.0010639 & $\begin{array}{l}\text { Negative regulation of } \\
\text { organelle organization }\end{array}$ & 3 & 0.0455 & $A U R K A, A U R K B, H M G A l$ \\
\hline
\end{tabular}

As indicated, there was a strong interaction between BIRC5, HMGA1, MYC, MYCN and AURKA/B, CDK1 and CDCA8, all of which are highly affiliated with processes that drive cellular mitosis. 
STRING protein network analysis mapped $H M G A 1$ to $M Y C N, S P 1, E 2 F 1$ and SREBP1 [a transcription factor with an important role in lipid metabolism, previously found to be highly activated in malignancies (47)], SREBP-cleavageactivating protein $[S C A P$ which plays a role in trafficking $S R E B P 1$ from the ER to the Golgi apparatus and recently found to play a role in tumorigenesis (48)], insulin-like growth factor receptor 1 [IGFIR or INSR, a known driver of HIF-2a transcription via PI3K signaling (49)] and the gene KITLG [which codes for the ligand of the tyrosine-kinase receptor c-KIT, STAT1 and STAT4 and implicated in the susceptibility of germ cell tumors such as testicular cancer $(50,51)]$. Furthermore, when we examined the networks linking only $H M G A 1, B I R C 5$ and $M Y C N$, we identified very strong interactions with the highly tumorigenic $A U R K A / B, C D K 1$, CDCA8 (52) and INCENP (53). As strong cell proliferation players, we speculate that the IMR-32 cells overexpressing HMGAl and MYCN have an enhanced mitotic and cell division capacity that favors tumor cell proliferation and the evasion of apoptosis. With HMGAl being a common player in the abovementioned tumorigenic pathways, including $H I F-1 \alpha, S R E B P 1$, $K I T L G, A U R K A / B, C D K 1$ and $C D C A 8$, it is no surprise that $M Y C N$-amplified IMR-32 cells or high-risk, $M Y C N$-amplified neuroblastomas are highly malignant cancers.

$F A B P 5$ binds with a strong affinity to medium and long chain fatty acids, and translocates them into the nucleus where they stimulate their nuclear receptor $P P A R \gamma$, which in turn stimulates other targets that lead to cancer expansion and progression by enhanced angiogenesis and reduced apoptosis (54). Based on previous studies that have shown FABP5 upregulation in various tumors, its association with cancer malignancy and invasiveness (55) and the demonstrated antitumor activity of the FABP5 chemical inhibitor SBFI26 (56), we decided to evaluate its role in the IMR-32 neuroblastoma cells. We were particularly interested in FABP5 as there are limited studies exploring its role in the aggressive, $M Y C N$-amplified neuroblastoma cells. We were very intrigued by the observation that $F A B P 5$ mapped to the highly tumorigenic MYC, SREBF1, SREBF 2 and KITLG pathways further explaining the malignant nature of the IMR-32 cells.

Survivin or BIRC5 expression is strongly upregulated in aggressive, high-risk neuroblastoma compared to normal tissues, adult malignancies and non-malignant fetal adrenal neuroblasts (57). This upregulation correlates with an unfavorable prognosis in patients with neuroblastoma $(58,59)$. BIRC5 is a key regulator of mitosis and programmed cell death or apoptosis (60) and the smallest member of the family of inhibitor-of-apoptosis proteins (IAPs) $(61,62)$. Thus, it is an ideal target for killing tumor cells specifically, while sparing healthy normal cells. We found BIRC5 to be highly affiliated with $H M G A 1, M Y C$ and $M Y C N$ in the AURKA/B pathways, which may be critical interactions that fuel IMR-32 cell proliferation and malignancy. In addition, STRING network analysis identified interactions between BIRC5 and IL3 [a stimulator of STATs and AKT pathways (63)] and HIF-l $\alpha$ [an angiogenic driver in oxygen-deprived solid tumors (64) previously reported to protect neuroblastoma cells from hypoxia-induced apoptosis (63)]. The common denominator here is $M Y C$, our validated targets affiliated either directly or indirectly (for example via $M Y C N$ ) with $M Y C$. Moreover, the intricate network between $M Y C, M Y C N, A U R K A / B$ and $N C A M 1$, and our targets L1-CAM, HMGAI, BIRC5 and FABP5 links them to highly proliferative, angiogenic and metastatic tumorigenic pathways.

The transcriptional KD of all our proteins significantly inhibited the proliferation of IMR-32 cells and FABP5 and MYCN KD inhibited early apoptosis, while FABP5 or HMGA1 KD inhibited cellular migration. The double-target transcriptional KD did not yield an additive effect on cell proliferation compared to single-target KD, implying that these proteins may signal through redundant proliferative pathways. In fact, HMGA1 and MYCN have been found to co-interact and HMGA1 was identified as a direct MYCN transcriptional regulator (46), which would explain the lack of an additive effect with combined, siRNA transcriptional KD of both targets, compared to single-target KD in our cells. Others have demonstrated the interplay between L1-CAM and EGFR in promoting cancer proliferation via ERK activation (65). ERK is a protein downstream of EGFR, platelet-derived growth factor receptor (PDGFR) and vascular endothelial growth factor (VEGFR) signaling, which are receptor tyrosine kinases that our validated proteins may signal through. For example, the FABP5-PPAR $\gamma$-VEGF signaling transduction axis has been reported to be the pivotal tumorigenic pathway in prostate cancer progression and malignancy (54). Furthermore, L1-CAM (66), HMGA1 (67) and MYCN (68), have all been reported to inhibit $\mathrm{p} 53$, thereby affecting cellular proliferation; in addition, L1-CAM (69), FABP5 (54) and MYCN all signal through the mTOR pathway via PI3K/AKT activation, and this may therefor explain the lack of an additive effect between single-target versus double-target KD on cell proliferation.

The fact that FABP5 and MYCN KD were able to induce early apoptosis of our IMR-32 cells at $48 \mathrm{~h}$ post-transfection implies that these proteins are crucial for cellular survival and thus early apoptotic rates were observed $48 \mathrm{~h}$ following their transcriptional KD. In support of our findings, Kawaguchi et al demonstrated the interaction of FABP5 with SP-1 and c-MYC (both determined by IPA to be upregulated in the IMR-32 compared to SK-N-SH cells) to enhance cellular proliferation in cancer cells and the anti-proliferative effects of FABP5, $S P 1$ or c-MYC silencing in prostate cancer cells (70). We have previously demonstrated the interplay between $M Y C N$ and $L 1$-CAM in conferring the radioresistance of IMR-32 cells (25) and $L 1-C A M$ has been previously reported to sustain $E R K, F A K$ and $P A K$ phosphorylation in apoptosis-resistant ovarian cancers, whereas its transcriptional KD sensitized ovarian carcinoma cells to apoptotic stimuli (71). We speculate that the interplay between L1-CAM, FABP5 and MYCN in this aggressive neuroblastoma cell line may be driving its malignant, apoptosis-resistant behavior. Of note, a recent study demonstrated the efficacy and safety of using the CE7 monoclonal antibody to target $L 1-C A M$ in a (CAR)-redirected T-cell mediated immuno-therapy for children with neuroblastoma (72), which has shown promise in providing both in vitro and in vivo antitumor activity in primary, metastatic and recurrent neuroblastoma.

Our proteins validated by western blot analysis mapped to highly tumorigenic, activated upstream regulators which may help explain the aggressive nature of these malignant $M Y C N$ amplified cells. Seeing all these tumorigenic players highly 
expressed in the IMR-32 neuroblastoma cells and of particular interest, their mapping to the activated upstream regulator, $M Y C N$ is quite intriguing and highlights the possible mechanisms responsible for the aggressive, malignant nature of these cells. For instance, ISNR, SPI, SREBF1, IL3 and HIF-1 $\alpha$, which enhance tumor cell survival under stress-hypoxic conditions that favor proliferative processes and angiogenesis, may function as strong 'accomplices' of the main 'culprit', MYCN, in driving the malignant, tumorigenic behaviors of the IMR-32 cell line. In addition, $A U R K A / B$ with its strong interaction with $H M G A 1, B I R C 5, M Y C$ and $M Y C N$, as well as the strong interaction between $L 1-C A M$ and the migratory and angiogenic players, including $E G F R, R A N B P 1, N C A M 1$ and $N R P 1$, may further be fueling the malignant propensity of the $M Y C N$-amplified IMR-32 cells and the high-risk childhood neuroblastomas.

In conclusion, neuroblastoma that presents at diagnosis with high-risk disease is extremely difficult to cure and longterm survival is rarely documented. It is of utmost importance to target the highly malignant, treatment evasive form of this disease with multi-modality therapeutic approaches. As demonstrated in the present study, the $M Y C N$-amplified IMR-32 cells express highly tumorigenic proteins that belong to pathways that govern metastasis, invasion and migration of cancer cells; cancer stem cell propagation and maintenance; cancer angiogenesis, proliferation and evasion of apoptosis. In addition, our observation that the transcriptional KD of one target simultaneously downregulated another tumorigenic target indicates that an important network of interplay exists between highly tumorigenic proteins in these malignant cancer cells.

To the best of our knowledge, we are the first to illustrate the molecular crosstalk between these tumorigenic proteins and their affiliation with highly tumorigenic pathways in the MYCN-amplified IMR-32 neuroblastoma cells. Future studies are warranted to explore these interactions and to elucidate the exact mechanisms of this crosstalk, both at the cellular level and in pre-clinical models. Multi-modality targeted therapy against several non-redundant tumorigenic pathways may cripple this devastating disease and hinder malignant recurrence that almost always resists therapy, leading to mortality in affected children.

\section{Acknowledgements}

This study was supported in part by the Sheik Zayed Institute for Pediatric Surgical Innovation and the Michael Sandler Cancer Research Fund and by grants from the National Center for Scientific Research in Lebanon (grant no. CNRS632). In addition, partial funding in support of this study was provided by the Lebanese American University School of Pharmacy Faculty Research and Development Award, as well as the University of Balamand, Department of Biology, Faculty Research funds. The authors would like to thank Dr Kristy Brown, former Assistant Professor at the Children's national Medical Center, Center for Genetic Medicine Research (Washington, DC, USA) and currently Principle Scientist at Solid Biosciences (Cambridge, MA, USA) for her assistance with the SILAC proteomics analysis. The authors would also like to thank Mr. Samer Bazzi, Research Assistant at the
Faculty of Medicine, University of Balamand, for conducting the apoptosis assays and analysis using flow cytometry.

\section{Competing interests}

The authors declare that they have no competing interests.

\section{References}

1. Louis CU and Shohet JM: Neuroblastoma: Molecular pathogenesis and therapy. Annu Rev Med 66: 49-63, 2015.

2. Smith MA, Seibel NL, Altekruse SF, Ries LA, Melbert DL, O'Leary M, Smith FO and Reaman GH: Outcomes for children and adolescents with cancer: Challenges for the twenty-first century. J Clin Oncol 28: 2625-2634, 2010.

3. Maris JM,Hogarty MD, Bagatell R and Cohn SL: Neuroblastoma. Lancet 369: 2106-2120, 2007.

4. Pinto NR, Applebaum MA, Volchenboum SL, Matthay KK, London WB, Ambros PF, Nakagawara A, Berthold F, Schleiermacher G, Park JR, et al: Advances in risk classification and treatment strategies for neuroblastoma. J Clin Oncol 33: 3008-3017, 2015.

5. Chevrier L, Meunier AC, Cochaud S, Muller JM and Chadéneau C: Vasoactive intestinal peptide decreases MYCN expression and synergizes with retinoic acid in a human MYCN-amplified neuroblastoma cell line. Int J Oncol 33: 1081-1089, 2008.

6. Matthay KK, Villablanca JG, Seeger RC, Stram DO, Harris RE, Ramsay NK, Swift P, Shimada H, Black CT, Brodeur GM, et al; Children's Cancer Group: Treatment of high-risk neuroblastoma with intensive chemotherapy, radiotherapy, autologous bone marrow transplantation, and 13-cis-retinoic acid. N Engl J Med 341: 1165-1173, 1999.

7. Stafman LL and Beierle EA: Cell proliferation in neuroblastoma. Cancers (Basel) 8: E13, 2016.

8. Nicolai S, Pieraccioli M, Peschiaroli A, Melino G and Raschellà G: Neuroblastoma: Oncogenic mechanisms and therapeutic exploitation of necroptosis. Cell Death Dis 6: e2010, 2015.

9. Suita S, Tajiri T, Kaneko M, Hirai M, Mugishima H, Sugimoto T and Tsuchida Y: Implications of MYCN amplification in patients with stage 4 neuroblastoma who undergo intensive chemotherapy. J Pediatr Surg 42: 489-493, 2007.

10. Brodeur GM: Neuroblastoma: Biological insights into a clinical enigma. Nat Rev Cancer 3: 203-216, 2003.

11. Goldsmith KC and Hogarty MD: Targeting programmed cell death pathways with experimental therapeutics: Opportunities in high-risk neuroblastoma. Cancer Lett 228: 133-141, 2005.

12. Kang JH, Rychahou PG, Ishola TA, Qiao J, Evers BM and Chung DH: MYCN silencing induces differentiation and apoptosis in human neuroblastoma cells. Biochem Biophys Res Commun 351: 192-197, 2006.

13. Ong SE, Blagoev B, Kratchmarova I, Kristensen DB, Steen H, Pandey A and Mann M: Stable isotope labeling by amino acids in cell culture, SILAC, as a simple and accurate approach to expression proteomics. Mol Cell Proteomics 1: 376-386, 2002.

14. Jensen ON, Wilm M, Shevchenko A and Mann M: Sample preparation methods for mass spectrometric peptide mapping directly from 2-DE gels. Methods Mol Biol 112: 513-530, 1999.

15. Formolo CA, Williams R, Gordish-Dressman H, MacDonald TJ, Lee NH and Hathout Y: Secretome signature of invasive glioblastoma multiforme. J Proteome Res 10: 3149-3159, 2011.

16. Chen EY, Tan CM, Kou Y, Duan Q, Wang Z, Meirelles GV, Clark NR and Ma'ayan A: Enrichr: Interactive and collaborative HTML5 gene list enrichment analysis tool. BMC Bioinformatics 14: 128, 2013.

17. Kuleshov MV, Jones MR, Rouillard AD, Fernandez NF, Duan Q, Wang Z, Koplev S, Jenkins SL, Jagodnik KM, Lachmann A, et al: Enrichr: A comprehensive gene set enrichment analysis web server 2016 update. Nucleic Acids Res 44: W90-7, 2016.

18. Abouantoun TJ, Castellino RC and MacDonald TJ: Sunitinib induces PTEN expression and inhibits PDGFR signaling and migration of medulloblastoma cells. J Neurooncol 101: 215-226, 2011.

19. Bayin NS, Frenster JD, Sen R, Si S, Modrek AS, Galifianakis N, Dolgalev I, Ortenzi V, Illa-Bochaca I, Khahera A, et al: Notch signaling regulates metabolic heterogeneity in glioblastoma stem cells. Oncotarget 8: 64932-64953, 2017. 
20. Gonzalez-Villasana V, Fuentes-Mattei E, Ivan C, Dalton HJ, Rodriguez-Aguayo C, Fernandez-de Thomas RJ, Aslan B, Del C Monroig P, Velazquez-Torres G, Previs RA, et al: $\mathrm{Rac} 1 / \mathrm{Pak} 1 / \mathrm{p} 38 / \mathrm{MMP}-2$ axis regulates angiogenesis in ovarian cancer. Clin Cancer Res 21: 2127-2137, 2015.

21. Fan Y, Gan Y, Shen Y, Cai X, Song Y, Zhao F, Yao M, Gu J and Tu H: Leptin signaling enhances cell invasion and promotes the metastasis of human pancreatic cancer via increasing MMP-13 production. Oncotarget 6: 16120-16134, 2015.

22. Li Y, Zhang J, He J, Zhou W, Xiang G and Xu R: MicroRNA-132 cause apoptosis of glioma cells through blockade of the SREBP-1c metabolic pathway related to SIRT1. Biomed Pharmacother 78: 177-184, 2016

23. Bao JM, He MY, Liu YW, Lu YJ, Hong YQ, Luo HH, Ren ZL, Zhao SC and Jiang Y: AGE/RAGE/Akt pathway contributes to prostate cancer cell proliferation by promoting $\mathrm{Rb}$ phosphorylation and degradation. Am J Cancer Res 5: 1741-1750, 2015.

24. Wang J, Qi Q, Feng Z, Zhang X, Huang B, Chen A, Prestegarden L, Li X and Wang J: Berberine induces autophagy in glioblastoma by targeting the AMPK/mTOR/ULK1-pathway. Oncotarget 7: 66944-66958, 2016.

25. Rached J, Nasr Z, Abdallah J and Abou-Antoun T: L1-CAM knock-down radiosensitizes neuroblastoma IMR-32 cells by simultaneously decreasing $\mathrm{MycN}$, but increasing PTEN protein expression. Int J Oncol 49: 1722-1730, 2016.

26. Fabian J, Opitz D, Althoff K, Lodrini M, Hero B, Volland R, Beckers A, de Preter K, Decock A, Patil N, et al: MYCN and HDAC5 transcriptionally repress CD9 to trigger invasion and metastasis in neuroblastoma. Oncotarget 7: 66344-66359, 2016.

27. Gangoda L, Keerthikumar S, Fonseka P, Edgington LE, Ang CS, Ozcitti C, Bogyo M, Parker BS and Mathivanan S: Inhibition of cathepsin proteases attenuates migration and sensitizes aggressive N-Myc amplified human neuroblastoma cells to doxorubicin. Oncotarget 6: 11175-11190, 2015.

28. Preis PN, Saya H, Nádasdi L, Hochhaus G, Levin V and Sadée W: Neuronal cell differentiation of human neuroblastoma cells by retinoic acid plus herbimycin A. Cancer Res 48: 6530$6534,1988$.

29. Schwab M, Alitalo K, Klempnauer KH, Varmus HE, Bishop JM, Gilbert F, Brodeur G, Goldstein M and Trent J: Amplified DNA with limited homology to myc cellular oncogene is shared by human neuroblastoma cell lines and a neuroblastoma tumor Nature 305: 245-248, 1983

30. Wang T, Zhang Z, Wang K, Wang J, Jiang Y, Xia J, Gou L, Liu M, Zhou L, He T, et al Inhibitory effects of BMP9 on breast cancer cells by regulating their interaction with preadipocytes/adipocytes. Oncotarget 8: 35890-35901, 2017.

31. Segerström L, Baryawno N, Sveinbjörnsson B, Wickström M, Elfman L, Kogner P and Johnsen JI: Effects of small molecule inhibitors of PI3K/Akt/mTOR signaling on neuroblastoma growth in vitro and in vivo. Int J Cancer 129: 2958-2965, 2011

32. Bäckman U and Christofferson R: The selective class III/V receptor tyrosine kinase inhibitor SU11657 inhibits tumor growth and angiogenesis in experimental neuroblastomas grown in mice. Pediatr Res 57: 690-695, 2005

33. Rawnaq T, Quaas A, Zander H, Gros SJ, Reichelt U, Blessmann M, Wilzcak W, Schachner M, Sauter G, Izbicki JR, et al: L1 is highly expressed in tumors of the nervous system: A study of over 8000 human tissues. J Surg Res 173: 314-319, 2012.

34. Gavert N, Ben-Shmuel A, Raveh S and Ben-Ze'ev A: L1-CAM in cancerous tissues. Expert Opin Biol Ther 8: 1749-1757, 2008.

35. Raveh S, Gavert N and Ben-Ze'ev A: L1 cell adhesion molecule (L1CAM) in invasive tumors. Cancer Lett 282: 137-145, 2009.

36. Ben-Arie A, Huszar M, Ben-Zvi N, Smirnov A, Altevogt P and Fogel M: The role of L1-CAM immunohistochemial staining in the diagnosis of abdominal-pelvic cancer of uncertain primary site in women. Eur J Surg Oncol 34: 795-799, 2008.

37. Bao S, Wu Q, Li Z, Sathornsumetee S, Wang H, McLendon RE, Hjelmeland AB and Rich JN: Targeting cancer stem cells through L1CAM suppresses glioma growth. Cancer Res 68: 6043-6048, 2008.

38. Cheng L, Wu Q, Huang Z, Guryanova OA, Huang Q, Shou W, Rich JN and Bao S: L1CAM regulates DNA damage checkpoint response of glioblastoma stem cells through NBS1. EMBO J 30: 800-813, 2011

39. Zhao WJ and Schachner M: Neuregulin 1 enhances cell adhesion molecule L1 expression in human glioma cells and promotes their migration as a function of malignancy. J Neuropathol Exp Neurol 72: 244-255, 2013

40. Zhao W: Comparison of L1 expression and secretion in glioblastoma and neuroblastoma cells. Oncol Lett 4: 812-816, 2012.
41. Ackermann MA, Petrosino JM, Manring HR, Wright $\mathrm{P}$ Shettigar V, Kilic A, Janssen PML, Ziolo MT and Accornero F: TGF- $\beta 1$ affects cell-cell adhesion in the heart in an NCAM1dependent mechanism. J Mol Cell Cardiol 112: 49-57, 2017.

42. Grosschedl R, Giese K and Pagel J: HMG domain proteins: Architectural elements in the assembly of nucleoprotein structures. Trends Genet 10: 94-100, 1994.

43. Tallini G and Dal Cin P: HMGI(Y) and HMGI-C dysregulation: A common occurrence in human tumors. Adv Anat Pathol 6: 237-246, 1999

44. Chiappetta G, Tallini G, De Biasio MC, Manfioletti G, Martinez-Tello FJ, Pentimalli F, de Nigris F, Mastro A, Botti G, Fedele M, et al: Detection of high mobility group I HMGI(Y) protein in the diagnosis of thyroid tumors: HMGI(Y) expression represents a potential diagnostic indicator of carcinoma. Cancer Res 58: 4193-4198, 1998.

45. Abe N, Watanabe T, Sugiyama M, Uchimura H, Chiappetta G, Fusco A and Atomi Y: Determination of high mobility group I(Y) expression level in colorectal neoplasias: A potential diagnostic marker. Cancer Res 59: 1169-1174, 1999.

46. Giannini G, Cerignoli F, Mellone M, Massimi I, Ambrosi C, Rinaldi C, Dominici C, Frati L, Screpanti I and Gulino A: High mobility group A1 is a molecular target for MYCN in human neuroblastoma. Cancer Res 65: 8308-8316, 2005.

47. Ru P, Hu P, Geng F, Mo X, Cheng C, Yoo JY, Cheng X, Wu X, Guo JY, Nakano I, et al: Feedback loop regulation of SCAP/SREBP-1 by miR-29 modulates EGFR signaling-driven glioblastoma growth. Cell Reports 16: 1527-1535, 2016.

48. Guo D: SCAP links glucose to lipid metabolism in cancer cells. Mol Cell Oncol 3: e1132120, 2016.

49. Mohlin S, Hamidian A, von Stedingk K, Bridges E, Wigerup C, Bexell D and Påhlman S: PI3K-mTORC2 but not PI3K-mTORC1 regulates transcription of HIF2A/EPAS1 and vascularization in neuroblastoma. Cancer Res 75: 4617-4628, 2015.

50. Hanes R, Grad I, Lorenz S, Stratford EW, Munthe E, Reddy CC, Meza-Zepeda LA and Myklebost O: Preclinical evaluation of potential therapeutic targets in dedifferentiated liposarcoma. Oncotarget 7: 54583-54595, 2016.

51. Poynter JN, Hooten AJ, Frazier AL and Ross JA: Associations between variants in KITLG, SPRY4, BAK1, and DMRT1 and pediatric germ cell tumors. Genes Chromosomes Cancer 51: 266-271, 2012.

52. Jiao DC, Lu ZD, Qiao JH, Yan M, Cui SD and Liu ZZ: Expression of CDCA 8 correlates closely with FOXM1 in breast cancer: public microarray data analysis and immunohistochemical study. Neoplasma 62: 464-469, 2015.

53. Gohard FH, St-Cyr DJ, Tyers $M$ and Earnshaw WC: Targeting the INCENP IN-box-Aurora B interaction to inhibit CPC activity in vivo. Open Biol 4: 140163, 2014.

54. Chamcheu JC, Chaves-Rodriquez MI, Adhami VM, Siddiqui IA, Wood GS, Longley BJ and Mukhtar H: Upregulation of $\mathrm{PI} 3 \mathrm{~K} / \mathrm{AKT} / \mathrm{mTOR}, \mathrm{FABP} 5$ and $\mathrm{PPAR} \beta / \delta$ in human psoriasis and imiquimod-induced murine psoriasiform dermatitis model. Acta Derm Venereol 96: 854-856, 2016.

55. Connolly RM, Nguyen NK and Sukumar S: Molecular pathways: Current role and future directions of the retinoic acid pathway in cancer prevention and treatment. Clin Cancer Res 19: 1651-1659, 2013.

56. Al-Jameel W, Gou X, Forootan SS, Al Fayi MS, Rudland PS, Forootan FS, Zhang J, Cornford PA, Hussain SA and Ke Y: Inhibitor SBFI26 suppresses the malignant progression of castration-resistant PC3-M cells by competitively binding to oncogenic FABP5. Oncotarget 8: 31041-31056, 2017.

57. Althoff K, Lindner S, Odersky A, Mestdagh P, Beckers A, Karczewski S, Molenaar JJ, Bohrer A, Knauer S, Speleman F, et al: miR-542-3p exerts tumor suppressive functions in neuroblastoma by downregulating Survivin. Int J Cancer 136: 1308-1320, 2015

58. Islam A, Kageyama H, Takada N, Kawamoto T, Takayasu H, Isogai E, Ohira M, Hashizume K, Kobayashi H, Kaneko Y, et al: High expression of Survivin, mapped to $17 \mathrm{q} 25$, is significantly associated with poor prognostic factors and promotes cell survival in human neuroblastoma. Oncogene 19: 617-623, 2000.

59. Azuhata T, Scott D, Griffith TS, Miller M and Sandler AD: Survivin inhibits apoptosis induced by TRAIL, and the ratio between survivin and TRAIL receptors is predictive of recurrent disease in neuroblastoma. J Pediatr Surg 41: 1431-1440, 2006.

60. Mita AC, Mita MM, Nawrocki ST and Giles FJ: Survivin: Key regulator of mitosis and apoptosis and novel target for cancer therapeutics. Clin Cancer Res 14: 5000-5005, 2008. 
61. Adida C, Berrebi D, Peuchmaur M, Reyes-Mugica M and Altieri DC: Anti-apoptosis gene, survivin, and prognosis of neuroblastoma. Lancet 351: 882-883, 1998

62. Hossain MM, Banik NL and Ray SK: Survivin knockdown increased anti-cancer effects of (-)-epigallocatechin-3-gallate in human malignant neuroblastoma SK-N-BE2 and SH-SY5Y cells. Exp Cell Res 318: 1597-1610, 2012.

63. Han L, Jorgensen JL, Brooks C, Shi C, Zhang Q, Nogueras González GM, Cavazos A, Pan R, Mu H, Wang SA, et al Antileukemia efficacy and mechanisms of action of SL-101, a novel anti-CD123 antibody conjugate, in acute myeloid leukemia. Clin Cancer Res 23: 3385-3395, 2017.

64. Yin CP, Guan SH, Zhang B, Wang XX and Yue SW: Upregulation of HIF-1 $\alpha$ protects neuroblastoma cells from hypoxia-induced apoptosis in a RhoA-dependent manner. Mol Med Rep 12: 7123-7131, 2015.

65. Yoon H, Min JK, Lee DG, Kim DG, Koh SS and Hong HJ: L1 cell adhesion molecule and epidermal growth factor receptor activation confer cisplatin resistance in intrahepatic cholangiocarcinoma cells. Cancer Lett 316: 70-76, 2012

66. Wang Y and Schachner M: The intracellular domain of L1CAM binds to casein kinase $2 \alpha$ and is neuroprotective via inhibition of the tumor suppressors PTEN and p53. J Neurochem 133: $828-843,2015$.

67. Puca F, Colamaio M, Federico A, Gemei M, Tosti N, Bastos AU, Del Vecchio L, Pece S, Battista S and Fusco A: HMGA1 silencing restores normal stem cell characteristics in colon cancer stem cells by increasing p53 levels. Oncotarget 5: 3234-3245, 2014.
68. Mazar J, Rosado A, Shelley J, Marchica J and Westmoreland TJ: The long non-coding RNA GAS5 differentially regulates cell cycle arrest and apoptosis through activation of BRCA1 and p53 in human neuroblastoma. Oncotarget 8: 6589-6607, 2017.

69. Doberstein K, Pfeilschifter J and Gutwein P: The transcription factor PAX2 regulates ADAM10 expression in renal cell carcinoma. Carcinogenesis 32: 1713-1723, 2011.

70. Kawaguchi K, Kinameri A, Suzuki S, Senga S, Ke Y and Fujii H: The cancer-promoting gene fatty acid-binding protein 5 (FABP5) is epigenetically regulated during human prostate carcinogenesis. Biochem J 473: 449-461, 2016.

71. Stoeck A, Gast D, Sanderson MP, Issa Y, Gutwein P and Altevogt P: L1-CAM in a membrane-bound or soluble form augments protection from apoptosis in ovarian carcinoma cells. Gynecol Oncol 104: 461-469, 2007.

72. Künkele A, Taraseviciute A, Finn LS, Johnson AJ, Berger C, Finney O, Chang CA, Rolczynski LS, Brown C, Mgebroff S, et al: Preclinical assessment of CD171-directed CAR T-cell adoptive therapy for childhood neuroblastoma: CE7 epitope target safety and product manufacturing feasibility. Clin Cancer Res 23: 466-477, 2017.

This work is licensed under a Creative Commons Attribution-NonCommercial-NoDerivatives 4.0 International (CC BY-NC-ND 4.0) License. 